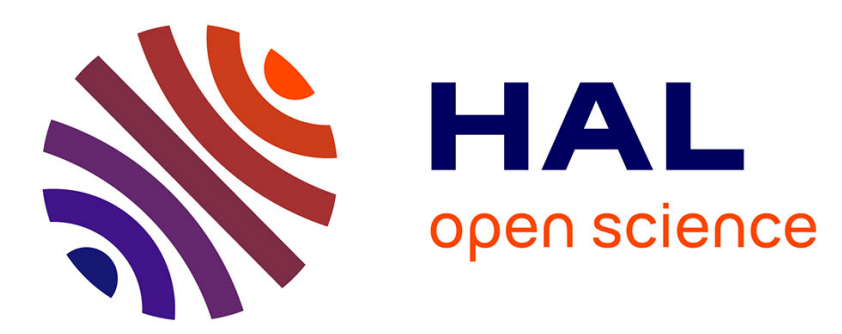

\title{
Electron-rich Coordination Receptors Based on Tetrathiafulvalene Derivatives: Controlling the Host-Guest Binding
}

\author{
Sébastien Goeb, Marc Sallé
}

\section{- To cite this version:}

Sébastien Goeb, Marc Sallé. Electron-rich Coordination Receptors Based on Tetrathiafulvalene Derivatives: Controlling the Host-Guest Binding. Accounts of Chemical Research, 2021, 54 (4), pp.10431055. 10.1021/acs.accounts.0c00828 . hal-03433121

HAL Id: hal-03433121

https://hal.science/hal-03433121

Submitted on 21 Nov 2021

HAL is a multi-disciplinary open access archive for the deposit and dissemination of scientific research documents, whether they are published or not. The documents may come from teaching and research institutions in France or abroad, or from public or private research centers.
L'archive ouverte pluridisciplinaire HAL, est destinée au dépôt et à la diffusion de documents scientifiques de niveau recherche, publiés ou non, émanant des établissements d'enseignement et de recherche français ou étrangers, des laboratoires publics ou privés. 


\section{Electron-Rich Coordination Receptors based on}

\section{Tetrathiafulvalene derivatives: Controlling the Host-}

\section{Guest binding}

Sébastien Goeb* and Marc Salle**

Univ Angers, CNRS, MOLTECH-ANJOU, 2 bd Lavoisier, F-49000 Angers, France.

CONSPECTUS. The coordination-driven self-assembly methodology has emerged over the last decades as an extraordinary versatile synthetic tool for obtaining discrete macrocyclic or cage structures. Rational approaches using wide libraries of ligands and metal complexes have allowed to reach more and more sophisticated discrete structures such as interlocked, chiral or heteroleptic cages, and some of them are designed for guest binding applications. Efforts have been notably produced in controlling host-guest affinity with in particular, an evident interest for targeting substrate transportation and subsequent delivering. Recent accomplishments in this direction were described from functional cages which can be addressed with light, $\mathrm{pH}$ or through a chemical exchange. The case of a redox-stimulation has been much less explored. In this case, the charge state of the redox-active cavity can be controlled through an applied electrical potential or introduction of an appropriate oxidizing/reducing chemical agent. Beyond possible applications in electrochemical sensing for environmental and medical sciences as well as for redox catalysis, controlling the cavity charge offers the possibility to modulate the host-guest binding affinity 
through electrostatic interactions, up to the point of disassembly of the host-guest complex, i.e. releasing of the guest molecule from the host cavity.

This Account highlights the key studies that we carried out at Angers, related to discrete redoxactive coordination-based architectures (i.e. metalla-rings, -cages and -tweezers respectively). These species are built upon metal-driven self-assembling between electron-rich ligands, based on the tetrathiafulvalene (TTF) moiety (as well as some of its S-rich derivatives), and various metal complexes. Given the high $\pi$-donating character of those ligands, the corresponding host structures exhibit a high electronic density on the cavity panels. This situation is favorable to bind complementary electron-poor guests, as it was illustrated with bis(pyrrolo)tetrathiafulvalene (BPTTF)-based cavities, which exhibit hosting properties for $\mathrm{C}_{60}$ or tetrafluorotetracyanoquinodimethane (TCNQ- $\left.\mathrm{F}_{4}\right)$. In addition to the pristine tetrathiafulvalene which was successfully incorporated into palladium- or ruthenium-based architectures, the case of the so-called extended tetrathiafulvalene (exTTF) appears particularly fascinating. A series of related polycationic and neutral $\mathrm{M}_{4} \mathrm{~L}_{2}$ ovoid containers, as well as $\mathrm{M}_{6} \mathrm{~L}_{3}$ cages, were synthesized and their respective binding abilities for neutral and anionic guests were studied. Remarkably, such structures allow to control the binding of the guest upon a redox-stimulation, through two distinctive processes i) cage disassembling, or ii) guest displacement. As an extension of this approach, metalla-assembled electron-rich tweezers were designed, which are able to trigger the guest release through an original process based on supramolecular dimerization activated through a redox stimulus. This ensemble of results illustrates the remarkable ability of electron-rich coordination-based self-assembled cavities to bind various types of guests and importantly, to trigger their release through a redox-stimulus. 


\section{KEY REFERENCES}

- Bivaud, S.; Balandier, J. Y.; Chas, M.; Allain, M.; Goeb, S.; Sallé, M. A Metal-Directed SelfAssembled Electroactive Cage with Bis(pyrrolo)tetrathiafulvalene (BPTTF) Side Walls. J. Am. Chem. Soc. 2012, 134, 11968-11970. ${ }^{1}$ The first example of a coordination driven self-assembled cage bearing the electron-rich tetrathiafulvalene (TTF) framework is described.

- Croué, V.; Goeb, S.; Szalóki, G.; Allain, M.; Sallé, M. Reversible Guest Uptake/Release by Redox-Controlled Assembly/Disassembly of a Coordination Cage. Angew. Chem. Int. Ed. 2016, $55,1746-1750 .^{2}$ The redox-triggered guest uptaking/releasing of a guest from a polycationic selfassembled cage is demonstrated for the first time.

- Szalóki, G.; Croué, V.; Carré, V.; Aubriet, F.; Alévêque, O.; Levillain, E.; Allain, M.; Arago, J.; Orti, E.; Goeb, S.; Sallé, M. Controlling the Host-Guest Interaction Mode through a Redox Stimulus. Angew. Chem. Int. Ed. 2017, 56, 16272-16276. ${ }^{3}$ A neutral self-assembled container constructed from the exTTF framework is able to redox-trigger the guest release of a neutral guest through to a guest exchange process.

- Krykun, S.; Dekhtiarenko, M.; Canevet, D.; Carré, V.; Aubriet, F.; Levillain, E.; Allain, M.; Voitenko, Z.; Sallé, M.; Goeb, S. Metalla-Assembled Electron-Rich Tweezers: Redox-Controlled Guest Release Through Supramolecular Dimerization. Angew. Chem. Int. Ed. 2020, 59, 716-720. ${ }^{4}$ A reversible redox-driven guest release occurring through an original dimerization process of a metalla-tweezer bearing the dithiafluorene (DTF) framework is depicted.

\section{INTRODUCTION}

The metal-assisted self-assembly strategy is effective for synthesizing, with high yields, various types of molecular polygons or polyhedra, i.e. geometries which are otherwise difficult to produce 
with traditional covalent synthesis pathways. ${ }^{5-11}$ Based on thermodynamic equilibria inherent to the labile coordination bonds, this strategy enables the construction of discrete species whose cavity can be exploited for recognizing guest entities. ${ }^{12-19}$ In some instances the latter can act as a template during the synthesis and allow for controlling the shape of the final structure. ${ }^{20-24}$ Responsive receptors are of strong interest to target applications. ${ }^{25-30}$ In particular, important efforts are currently devoted to design host systems which are not only able to bind a specific guest, but also to trigger the subsequent guest release through an external stimulus. ${ }^{31}$ This issue is of high interest from a fundamental point of view, but also for targeting various applications such as drug delivery, detection or capture of chemical agents (hazardous/pollutants/toxic), or catalysis in confined spaces. ${ }^{32}$ Outstanding results in this direction were recently described with coordination cages sensitive to various specific stimuli, such as light, ${ }^{33-36} \mathrm{pH}^{37,38}$ or addition of a chemical. ${ }^{39-43}$ Metalla-hosts able to operate by electron transfer have also to be considered. By analogy to the plethoric work of J. F. Stoddart on covalent receptors, ${ }^{44-46}$ the use of a reversible redox couple should in principle allow, once the release has taken place, for regenerating the initial coordination host by changing the applied potential without producing any waste.

Very few examples of guest release based on a redox stimulus were known when we started our research program. They mainly concern a redox modulation led on the guest itself $f^{47,48}$ rather than a redox reaction affecting the ionic charge of the host cavity. In addition, and despite an always increasing number of electroactive metalla-cages, ${ }^{49-56}$ only few of them involve a redox-active cavity and moreover their constituting ligands are mostly based on electron-deficient frameworks such as triazine ${ }^{57-59}$, perylene diimide, ${ }^{60-63}$ or naphthalene diimide ${ }^{64}$ Some can be oxidized, ${ }^{65}$ but their electron-activity is most often localized on the outside of the cage cavity with pendant covalently linked redox-active groups ${ }^{66}$ rather than centered on the cavity. On this basis, electron- 
rich cavities whose ionic charge can be tuned upon oxidation are of strong interest as they should: i) promote the encapsulation of electron-deficient antagonistic species, ii) generate a positively charged cavity upon oxidation, likely to modify the host-guest affinity and possibly lead to guest releasing, and iii) allow a reversible guest-binding process upon subsequent reduction.

In this Account we highlight our recent developments and contributions concerning the preparation of metalla-assembled rings, cages and tweezers incorporating the electron-rich tetrathiafulvalene (TTF) motifs or some of its S-rich derivatives (Scheme 1). Because of its unique electrochemical properties, characterized by two stable and easily accessible oxidized states (i.e. $\mathrm{TTF}^{\bullet+}$ and $\mathrm{TTF}^{2+}$ ), the TTF moiety has been widely exploited for the preparation of supramolecular switchable systems ${ }^{67-69}$ and conducting materials. ${ }^{70-72}$ The TTF skeleton and its derivatives are essentially planar and correspond to highly $\pi$-extended systems. Such two-dimensional geometry is suitable to build redox-active host cavities upon self-assembling whose, importantly, ionic charge can be tuned depending on the redox state of the TTF-based constituents.

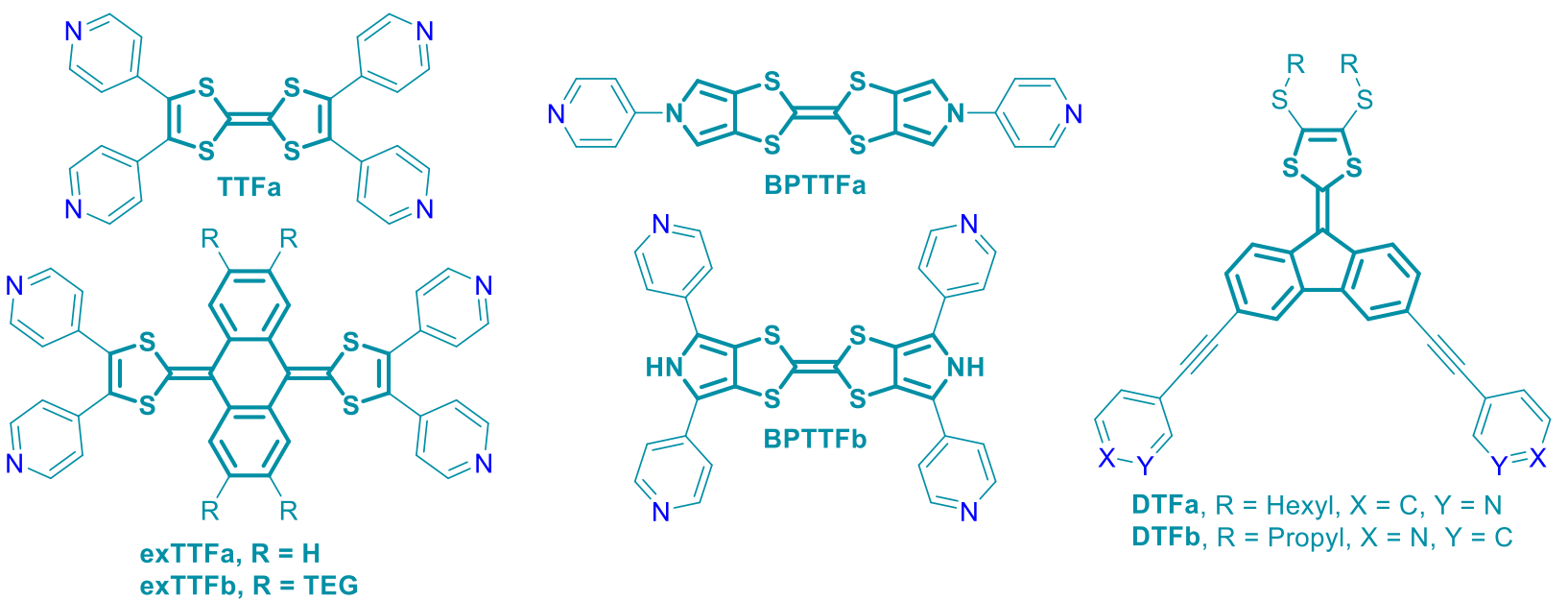

Scheme 1. Building blocks used in this research program. In bold are highlighted the electron-rich TTF $\left(E_{1}{ }^{\mathrm{ox}}=0.01 \mathrm{~V}, E_{2}{ }^{\mathrm{ox}}=0.36 \mathrm{~V}\right.$ vs FcH/FcH $\left.{ }^{+}\right)$, exTTF $\left(E_{1}{ }^{\mathrm{ox}}=-0.04 \mathrm{~V}\right.$ vs FcH/FcH $\left.{ }^{+}\right)$, BPTTF 
$\left(E_{1}{ }^{\mathrm{ox}}=-0.02 \mathrm{~V}, E_{2}{ }^{\mathrm{ox}}=0.23 \mathrm{~V}\right.$ vs $\left.\mathrm{FcH} / \mathrm{FcH}^{+}\right)$and $\mathbf{D T F}\left(E_{1}{ }^{\mathrm{ox}}=0.35 \mathrm{~V}\right.$ vs $\left.\mathrm{FcH} / \mathrm{FcH}^{+}\right)$moieties from which they are synthetized (Oxidation potentials correspond to naked moieties).

\section{TTF-based cages}

The preparation of TTF-based self-assembled structures requires the prior synthesis of TTFbased ligands. This can be achieved by substituting the TTF framework with coordinating pyridyl units. Some 1,1'-disubstituted TTF derivatives have been already described. Depending on the relative positions of the substituents, they exist as $Z$ and $E$ isomers which are known to readily isomerize. ${ }^{73,74}$ Such configurational instability is not appropriate for self-assembling purposes, and we therefore targeted instead the tetrasubstituted TTF analogue TTFa. The latter could be obtained in one step through a pallado-catalyzed tetraarylation reaction using C-H activation (Figure 1) ${ }^{75}$ 

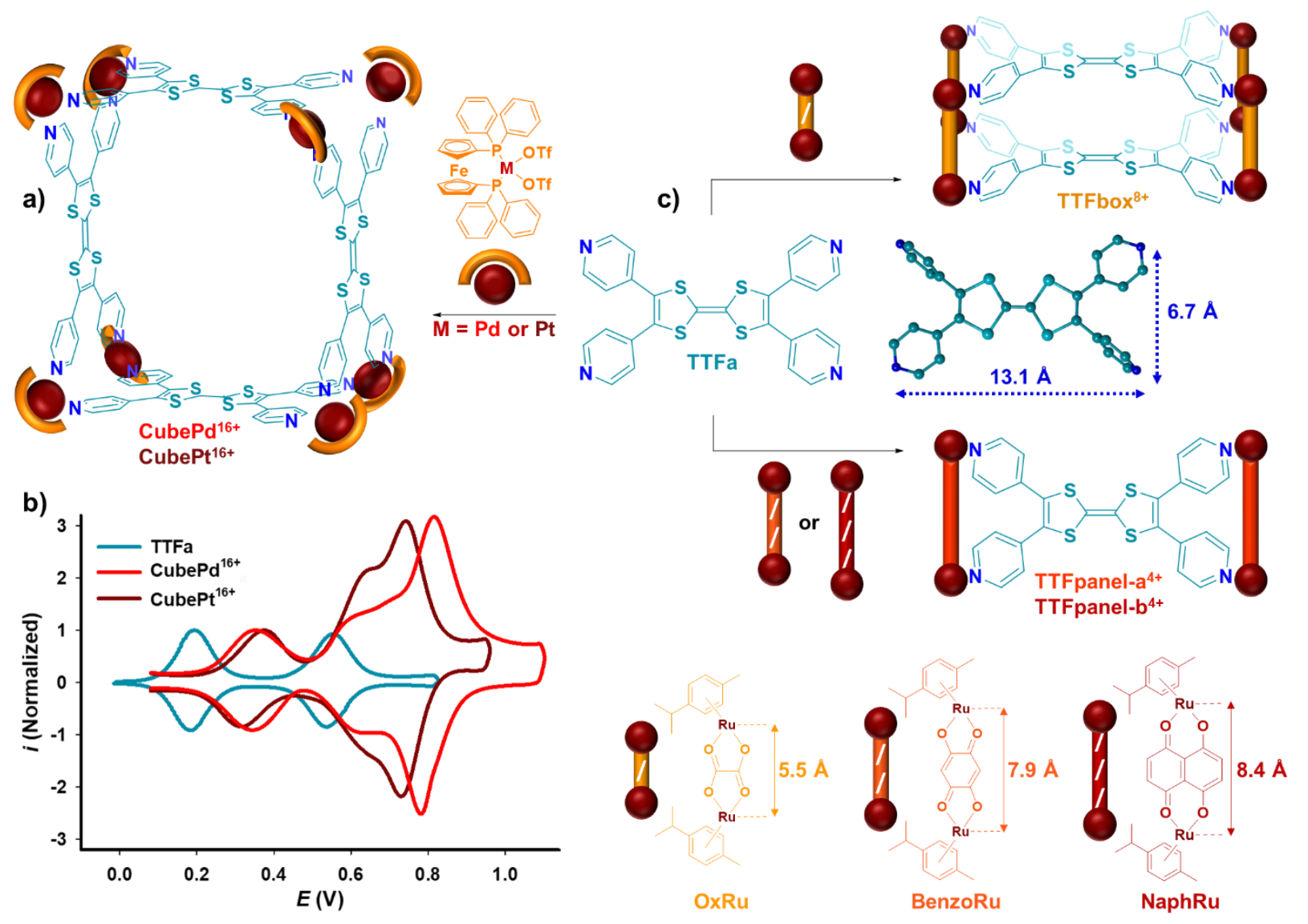

Figure 1. (a) Synthesis of CubePd ${ }^{16+}$ and CubePt $\mathbf{C}^{16+.76}$ (b) Deconvoluted cyclic voltammograms of CubePd ${ }^{16+}$ and $\mathbf{C u b e P t}^{16+}\left(c=0.5 \mathrm{mM}, \mathrm{CH}_{3} \mathrm{CN}^{16} \mathrm{CH}_{2} \mathrm{Cl}_{2} 1 / 1,0.1 \mathrm{M} \mathrm{nBu} 4 \mathrm{NPF}_{6}, 20 \mathrm{mV} \cdot \mathrm{s}^{-1}, \mathrm{~V}\right.$ vs $\mathrm{FcH} / \mathrm{FcH}^{+}$); (c) X-Ray crystal structure of TTFa and synthesis of TTFbox ${ }^{8+}$, TTFpanel-a ${ }^{4+}$ and TTFpanel-b ${ }^{4+} \cdot{ }^{77}$

A first family of TTF based self-assembled discrete structures was synthetized upon the reaction of TTFa with $\mathrm{M}(\mathrm{dppf})(\mathrm{OTf})_{2}$ complexes $(\mathrm{M}=\mathrm{Pd}$ or $\mathrm{Pt}, \quad \mathrm{dppf}=1,10-$ bis(diphenylphosphino)ferrocene, OTf $=$ trifluoromethane sulfonate) $\left(\right.$ Figure 1a). ${ }^{76}{ }^{1} \mathrm{H}$ DOSY NMR experiments, from which hydrodynamic radius of $17 \AA$ was calculated, ${ }^{78}$ and FTICR-HRMS analysis, revealed the formation of $\mathrm{M}_{4} \mathrm{~L}_{8}$ species $\mathbf{C u b e P d}{ }^{16+}$ and $\mathbf{C u b e P t}^{\mathbf{1 6 +}}$ respectively. Cyclic voltammetry experiments show the presence of three reversible oxidation processes. The first two 
$\left(E_{1}{ }^{\mathrm{ox}}=0.3 \mathrm{~V}, E_{2}{ }^{\mathrm{ox}}=0.6 \mathrm{~V}\right)$ are assigned to oxidation of TTF moieties and the third one $\left(E_{3}{ }^{\mathrm{ox}}=\right.$ $0.75 \mathrm{~V})$, to the peripheral ferrocene units. Eight ferrocene units are therefore simultaneously oxidized and can be used as an internal reference to address the number of electrons exchanged on both TTF redox processes. The $1 / 1 / 2$ relative peak intensities of the $E_{1}{ }^{\text {ox }}, E_{2}{ }^{\text {ox }}$ and $E_{3}{ }^{\text {ox }}$ redox waves, determined from the deconvoluted cyclic voltammograms, indicate that the four TTF moieties behave independently and that a total of sixteen positive charges (TTF: 4x2e $\mathrm{e}^{-}$FcH: $8 \times 1 \mathrm{e}^{-}$ ) can be reversibly generated upon complete oxidation. $\mathbf{C u b e P d}{ }^{16+}$ and $\mathbf{C u b e P t}^{16+}$ constitute the first examples of discrete self-assembled coordination complexes bearing TTF side walls which are built following a self-assembly strategy. ${ }^{76}$ The binding property of these tetragonal prisms was evaluated but no convincing result was observed, which was attributed to the very large cavity size which does not allow a concerted interaction of TTF units for binding a guest.

We conducted, in collaboration with B. Therrien and coworkers, an alternative project dealing with TTF-based self-assembled systems and using $\mathrm{Ru}$ complexes (Figure 1c). ${ }^{77}$ The latter correspond to bis-ruthenium arene complexes, in which the $\mathrm{Ru}-\mathrm{Ru}$ distance can be tuned as a function of the conjugated tetraoxolene bridge (OxRu, BenzoRu and NaphRu) (Figure 1c bottom). Therefore these bimetallic complexes can afford "sandwich" type compounds in which two ligands face each other with a controlled distance. ${ }^{79}$ On this basis, reaction of ligand TTFa with the bis-ruthenium complexes produced the $\mathrm{M}_{8} \mathrm{~L}_{2}$ cage species TTFbox $^{8+}$ (in the case of

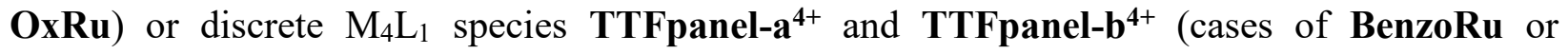
NaphRu) (Figure 1c). The unexpectedly selective formation of the $\mathrm{M}_{4} \mathrm{~L}_{1}$ complexes instead of the targeted molecular boxes when using BenzoRu and NaphRu precursors results from the good size matching between the lateral extension of the ligand (Npyr ${ }^{\cdots}$ Npyr intramolecular distance) and the bis-ruthenium complex ( $\mathrm{Ru} \cdots \mathrm{Ru}$ intramolecular distance). Electrochemical experiments conducted 
on these compounds revealed significantly different behaviors. While complexes TTFpanel-a ${ }^{4+}$ and TTFpanel-b ${ }^{4+}$ show the typical signature of TTF moieties, with two successive and reversible oxidation waves, $\mathbf{T T F b o x}{ }^{8+}$ exhibits only one single reversible oxidation process. Such a deviation from the usual electrochemical behavior of TTF derivatives was already reported ${ }^{80,81}$ and is attributed to the rigidity of the metalla-assembly. Therefore, contrary to isolated TTF units which are flexible in both oxidized states (free rotation around the central C-C bond), the TTFbox ${ }^{8+}$ cage does not grant such a conformational freedom, which likely modifies the kinetics of the redox processes.

\section{Bis(Pyrrolo)TTF-based rings and cages}

The case of the bis(pyrrolo)TTF building block (BPTTF) (Scheme 1) is interesting since $i$ ) this system displays similar electronic properties as TTF (i.e. two successive and reversible oneelectron oxidation steps at low potentials) and, ii) contrary to the latter, BPTTF allows to obtain difunctionalized derivatives which are devoid of $\mathrm{Z} / \mathrm{E}$ isomerization issues, through $\mathrm{N}, \mathrm{N}^{\prime}-$ difunctionalization. On this basis, we synthetized BPTTFa (Figure 2a). ${ }^{82,83}$ In principle, such a linear ligand can be combined to a cis-blocked square planar Pd(II) or Pt(II) complex, as in the case of the seminal works of M. Fujita ${ }^{84}$ or P. Stang ${ }^{85}$ who used 4,4'-bipyridyl ligand, from which molecular squares can be obtained. Reaction of BPTTFa with the bulky cis-blocked $(\mathrm{dppp}) \mathrm{Pt}(\mathrm{OTf})_{2}(\mathrm{dppp}=(\mathrm{bis})$ diphenylphosphinopropane; OTf $=$ triflate $)$ complex led to the precipitation of Square ${ }^{8+}$ with a $30 \%$ yield, while the triangular homologue $\left(\right.$ Triangle $^{6+}$ ) remains in solution and is isolated in a $60 \%$ yield upon evaporation (Figure 2a) ${ }^{86}$ Such separation of both polygons is quite unusual since it is known that using long and/or flexible ligands usually leads to a mixture of triangular and square polygons in equilibrium, ${ }^{87}$ which are difficult to separate. Cyclic 
voltammetry experiments carried out in the presence of ferrocene $(\mathrm{FcH})$ as a reference, revealed that every BPTTF units of Triangle $^{6+}$ and Square $^{8+}$ is reversibly oxidized and behaves analogously to other BPTTF derivatives, i.e. through two reversible waves at low oxidation potential (Figure $2 \mathrm{~b}$ ). Modelling these polygons shows that the $\pi$-donating triangle exhibits a cavity whose size and shape can be suitable to accommodate one electron-deficient $\mathrm{C}_{60}$ fullerene molecule (Figure 2c). Indeed, UV-vis titration studies show a 1:1 stoichiometry between Triangle ${ }^{6+}$ and $\mathrm{C}_{60}$ with a good association constant of $1.6 \times 10^{4}$ in a $\mathrm{CS}_{2} / \mathrm{CH}_{2} \mathrm{Cl}_{2}(8 / 2)$ mixture. This result constitutes a first evidence for the relevance of the metal-directed self-assembly strategy in the design of electron-rich cavities for binding electron-deficient species. 
a)
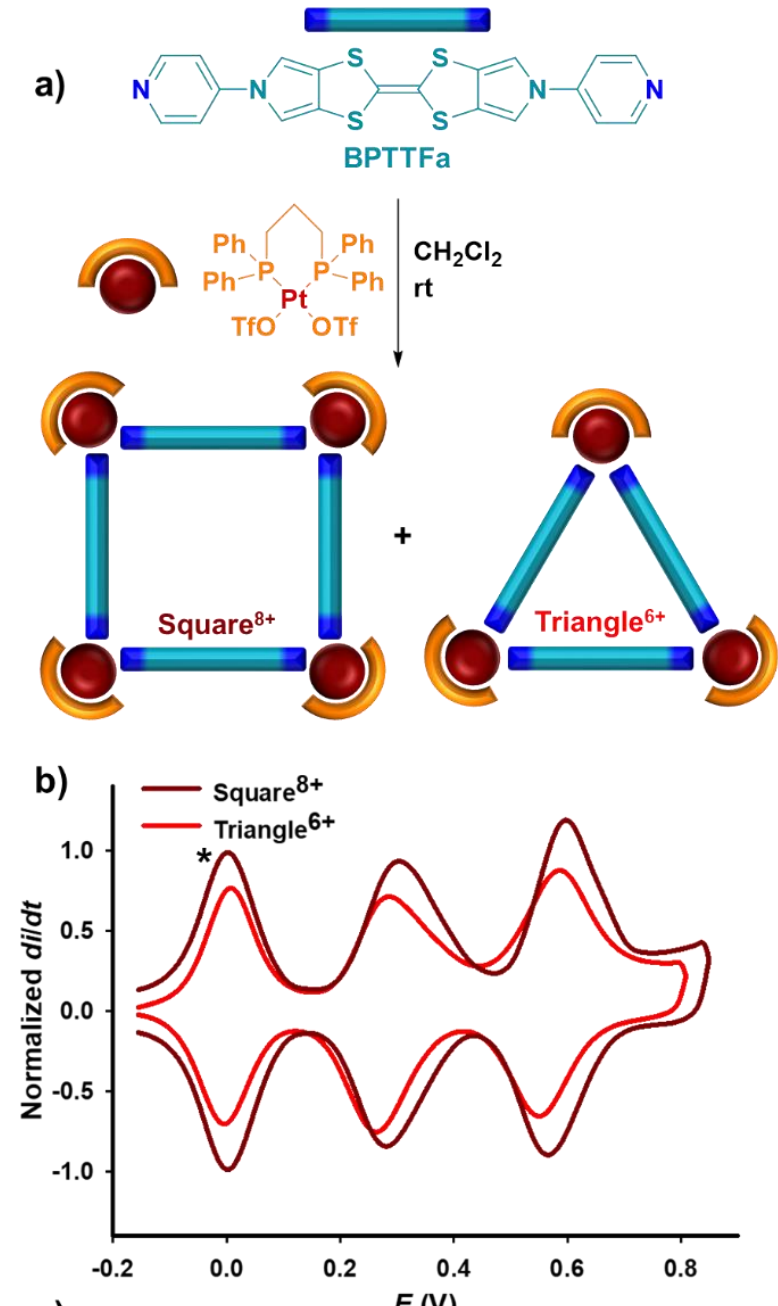

c)

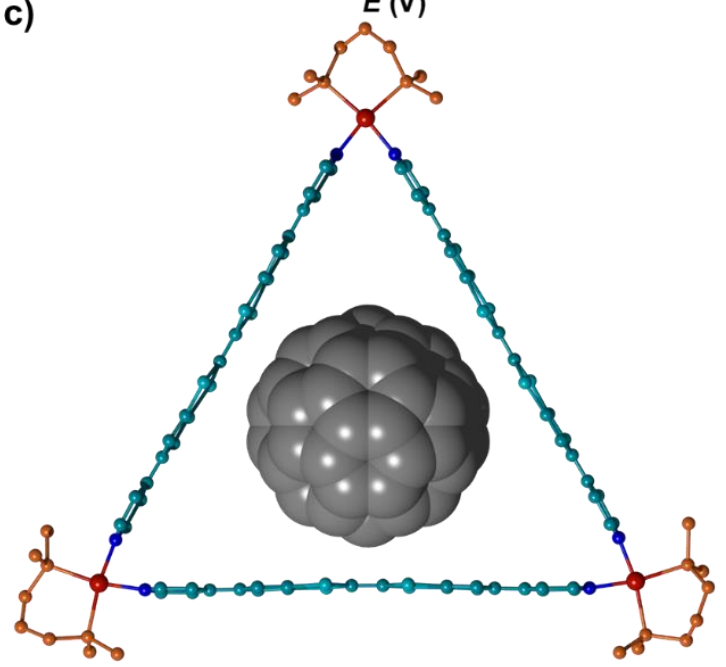

Figure 2. (a) Synthesis of Square ${ }^{8+}$ and Triangle ${ }^{6+}$; (b) Deconvoluted cyclic voltammograms of Square $^{8+}$ and Triangle $^{6+}$ in presence of 4.0 and 3.0 equiv. of ferrocene $\left(^{*}\right)$ respectively $(c=0.5$ 
$\mathrm{mM}, \mathrm{CH}_{3} \mathrm{CN}, 0.1 \mathrm{M} \mathrm{nBu} 4 \mathrm{NPF}_{6}, 20 \mathrm{mV} \cdot \mathrm{s}^{-1}, \mathrm{~V}$ vs $\mathrm{FcH} / \mathrm{FcH}^{+}$); (c) Molecular force field (MM+) model of $\mathrm{C}_{60} \subset$ Triangle $^{6+} .82,86$

The BPTTF skeleton was also functionalized with four coordinating pyridyl units to afford BPTTFb (Figure 3a). This new ligand was reacted with cis-Pt $\left(\mathrm{PEt}_{3}\right)_{2} \mathrm{OTf}_{2}$ in DMSO and afforded the $\mathrm{M}_{6} \mathrm{~L}_{3}$ metallaprism Prism ${ }^{12+}$ (Figure 3b). ${ }^{1}$
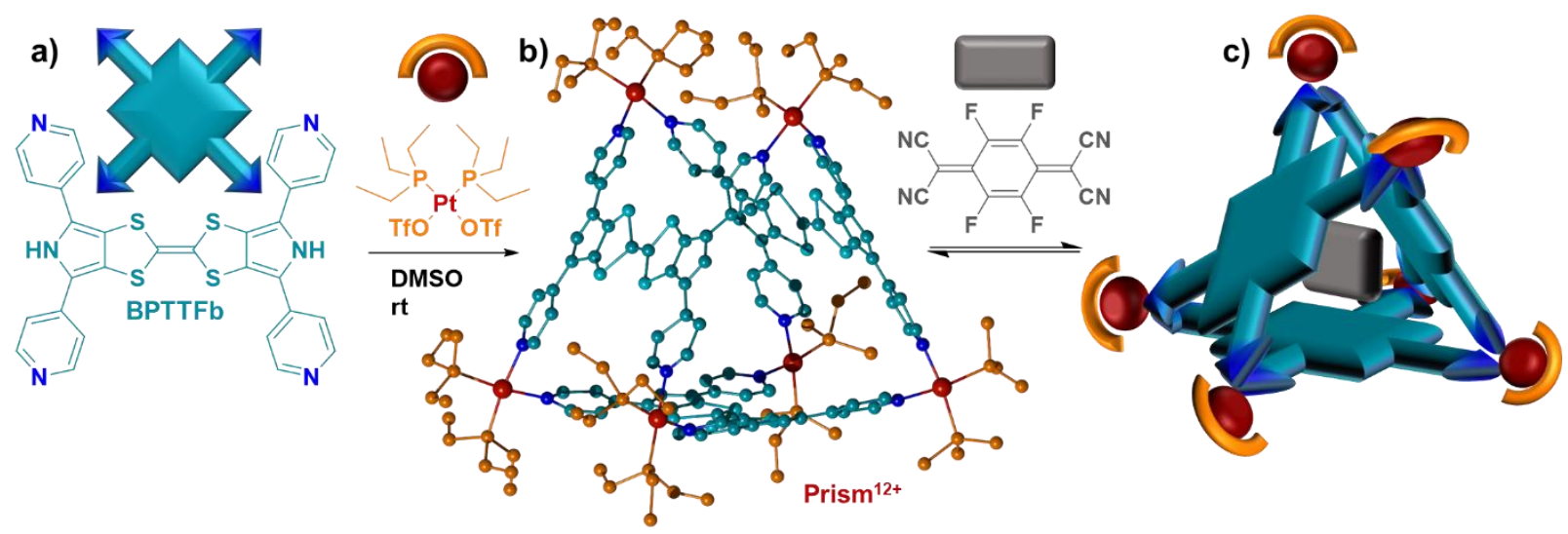

Figure 3. (a) Synthesis of Prism ${ }^{12+}$; (b) X-Ray crystal structure of Prism ${ }^{12+}$; (c) cartoon illustrating the inclusion complex TCNQ- $\mathrm{F}_{4} \subset$ Prism $^{12+}$.

Cyclic voltammetry studies of Prism ${ }^{12+}$ show two successive oxidation processes, reflecting the electronic independence of the three BPTTF units. The corresponding cavity is about $8 \AA$ in diameter and is formed by three electron-rich BPTTF-based ligands affording a cavity which in principle, should be appropriate for inclusion of electron-poor derivatives. This was indeed demonstrated through complexation of one tetrafluorotetracyanoquinodimethane (TCNQ- $\mathrm{F}_{4}$ ) molecule within the cavity. Though this study corresponds to the first example of a three dimensional TTF-based metalla-assembled structure which is able to bind an electron-poor guest, ${ }^{1}$ monitoring the host-guest affinity could not be operated electrochemically. 


\section{3. exTTF-based cages}

The so-called extended-TTF derivative (exTTF; 9,10-di(1,3-dithiol-2-ylidene)-9,10-

dihydroanthracene) (Scheme 1) has been the subject of intense interest, motivated by a unique combination of electronic and geometrical properties. ${ }^{88-91}$ In particular, this fascinating compound exists in a singular "butterfly-shaped" structure in the neutral state, induced by the steric hindrance between the peri-planar hydrogens of the central anthraquinonoid skeleton and the sulfur atoms of both 1,3-dithiole heterocycles. Therefore, unlike the quasi-planar TTF and BPTTF derivatives, this electron-rich motif presents a single pseudo-reversible oxidation process, involving two electrons and leading to a fully aromatic dicationic species. Remarkably, this oxidation process is accompanied by a geometric transformation leading to a relaxed dicationic species, in which both aromatic 1,3-dithiolium units are now connected to the central anthracene moiety through rotation around the C-C bond (Figure $4 b, c)$. 
a)

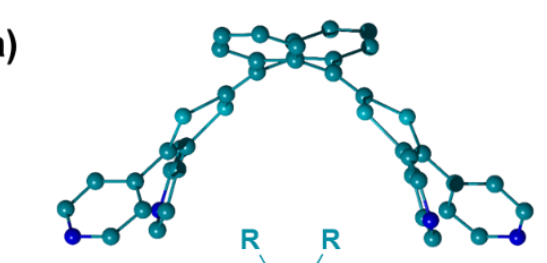

b)

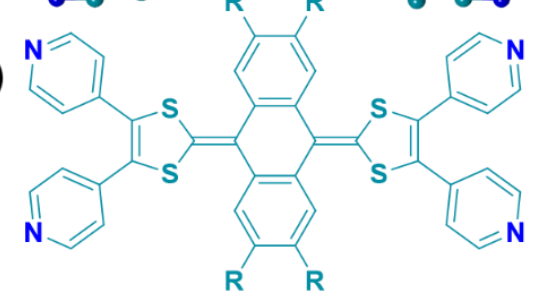

$\mathrm{R}=\mathrm{H}$, exTTFa

$\mathrm{R}=\mathrm{TEG}$, exTTFb

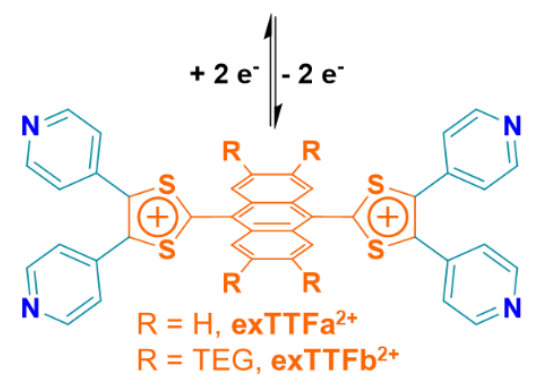

c)

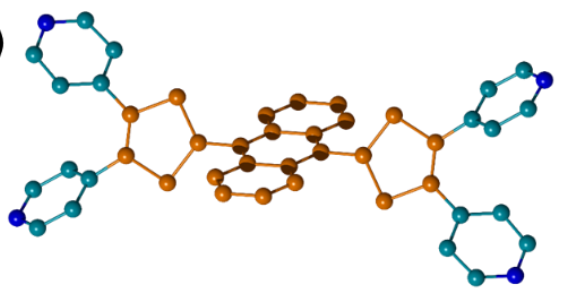

Figure 4. (a) X-Ray crystal structure of ligand exTTFa; (b) Ligands exTTFa $(R=H)$ and exTTFb $\left(\mathrm{R}=\right.$ TEG: $\left.-\left(\mathrm{OCH}_{2} \mathrm{CH}_{2}\right)_{3}-\mathrm{OCH}_{3}\right)$ and their corresponding oxidized species exTTFa ${ }^{2+}$ and $\mathbf{e x T T F b}^{2+}$; (c) Electrocrystallized crystal structure of ligand exTTFa ${ }^{2+} \cdot{ }^{92}$

Given this unique combination of electronic and conformational properties, i.e. a drastic and reversible change of the molecular shape upon oxidation, we were interested in designing selfassembled cages based on this motif. Our objective was to exploit this very specific behavior for controlling host-guest binding processes and more generally supramolecular transformations. ${ }^{28,92}$

For this purpose, we synthetized the tetra-functionalized ligand exTTFa (Figure 4b) in one step from pristine exTTF, using the same procedure as for TTF derivatives (see above). ${ }^{75}$ Reaction of 
exTTFa with the enPd( $\left(\mathrm{NO}_{3}\right)_{2}$ complex (en = ethylenediamine) in DMSO-d 6 afforded a single species with an estimated hydrodynamic radius of $c a 17 \AA$. Complementary FTICR-HRMS analysis and X-Ray diffraction experiments revealed the formation of the trigonal prismatic complex Pd6(exTTFa) $3{ }^{12+}$ presenting a cavity of $17.7 \AA$ x $19.0 \AA$ x $9.5 \AA$ (Figure $\left.5 \mathrm{a}\right) .{ }^{93}$ No binding ability could be demonstrated for this complex, even for large substrates such as fullerene derivatives.

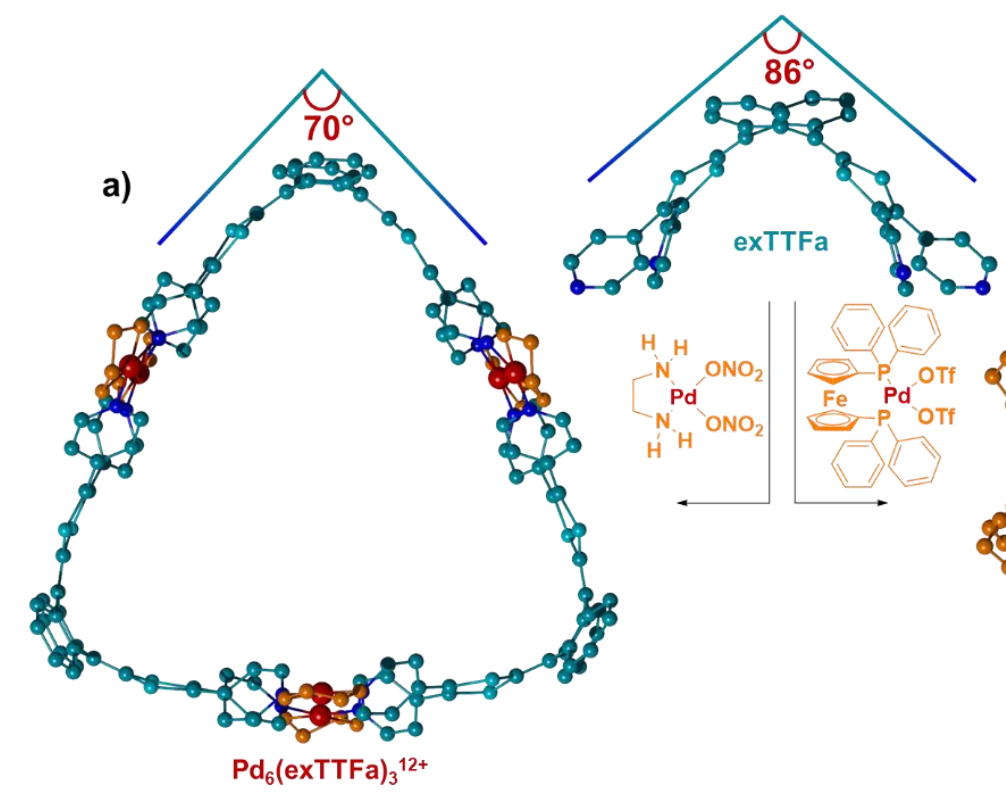

Figure 5. Synthesis and X-ray structures of (a) $\mathbf{P d}_{6}(\mathbf{e x T T F a}) \mathbf{3}^{\mathbf{1 2 +}}$ and (b) $\mathbf{P d}_{4}(\mathbf{e x T T F a})_{2}{ }^{\mathbf{8 +}} \cdot{ }^{93,94}$

In order to favor a smaller cavity, we subjected the same ligand to the bulky $\operatorname{Pd}(\mathrm{II})$ complex $\operatorname{Pd}(\mathrm{dppf})(\mathrm{OTf})_{2}(\mathrm{dppf}=1,10$-bis(diphenylphosphino)ferrocene) (Figure $5 \mathrm{~b})$. Whereas the enPd( $\left(\mathrm{NO}_{3}\right)_{2}$ complex leads to a $\mathrm{M}_{6} \mathrm{~L}_{3}$ structure, the reaction with $\mathrm{Pd}(\mathrm{dppf})(\mathrm{OTf})_{2}$ affords a much more constrained $\mathrm{M}_{4} \mathrm{~L}_{2}$ discrete species $\mathbf{P d}_{4}(\mathbf{e x T T F a}){ }_{2}{ }^{8+}$ (Figure 5b), in which the exTTF moiety curvature is strongly accentuated compared to the starting ligand. This observation illustrates the critical role of peripheral coligands upon the geometry of the final discrete self-assembled structure. ${ }^{93}$ This new $\mathrm{M}_{4} \mathrm{~L}_{2}$ cage structure shows an original electron-rich ovoid cavity of $15 \AA \mathrm{x}$ 
9.5 A. Given these dimensions, its ability to encapsulate flat neutral molecules was evaluated. Though the scope of this study was limited by solubility issues, the formation of a $1 / 1$ host-guest inclusion complex with perylene was characterized by FTICR-HRMS and an association constant of $3.9 \times 10^{3}$ was calculated by DOSY NMR in $\mathrm{CD}_{3} \mathrm{NO}_{2}{ }^{94}$

In order to limit the complexation/solvation competition, there is a need to design cages which are soluble in a wider range of solvents. We synthetized therefore the exTTFb ligand incorporating triethylene glycol monomethyl ether (TEG) chains (Figure 4b). ${ }^{2}$ This molecule displays a double advantage: in addition to presenting a better solubility, the presence of oxygen atoms on the anthraquinonoid core contributes to increase the $\pi$-donating character of the molecule. As expected, this ligand self-assembles with the $\mathrm{Pd}(\mathrm{dppf})(\mathrm{OTf})_{2}$ complex, the same way as its parent exTTFa, to quantitatively form the $\mathrm{M}_{4} \mathrm{~L}_{2} \mathrm{Pd}_{4}(\mathbf{e x T T F b})_{2}{ }^{8+}$ edifice. Despite the presence of the flexible TEG chains, single crystals were obtained and the crystal structure was determined by Xray diffraction (Figure 7a). This structure differs essentially from that of $\mathbf{P d}_{4}(\mathbf{e x T T F a}) \mathbf{2}^{\mathbf{8 +}}$ by the presence of triethylene glycol chains and exhibits similar binding properties for polyaromatic guests in nitromethane.

We also explored the presence of the positive charges on metal corners in $\mathbf{P d} 4(\mathbf{e x T T F b}) 2^{8+}$ for substrate encapsulation. ${ }^{2}$ The icosahedral anion potassium dodecafluoro-closo-dodecaborate $\left(\mathrm{B}_{12} \mathrm{~F}_{12}{ }^{2-}, 2 \mathrm{~K}^{+}\right)$proved to be an ideal candidate. Its shape, size and negative charge are complementary in all respects to the cavity. NMR, FTICR-HRMS and X-ray diffraction studies showed the inclusion of two anions inside the cavity (Figure 6a). In the solid state, each $\mathrm{B}_{12} \mathrm{~F}_{12}{ }^{2-}$ anion is located between two Pd(II) cations with a distance Pd $\cdots F$ of $3.3 \AA$, which is less than the sum of the van der Waals radii $(\approx 3.8 \AA)$, indicative of an electrostatic interaction. Consequently, the geometry of the cavity in this host-guest complex is partially modified towards a more spherical 
shape with respect to that of empty cage. As expected, the lateral TEG chains bind $\mathrm{K}^{+}$counter ions, which probably facilitates the crystallization process.

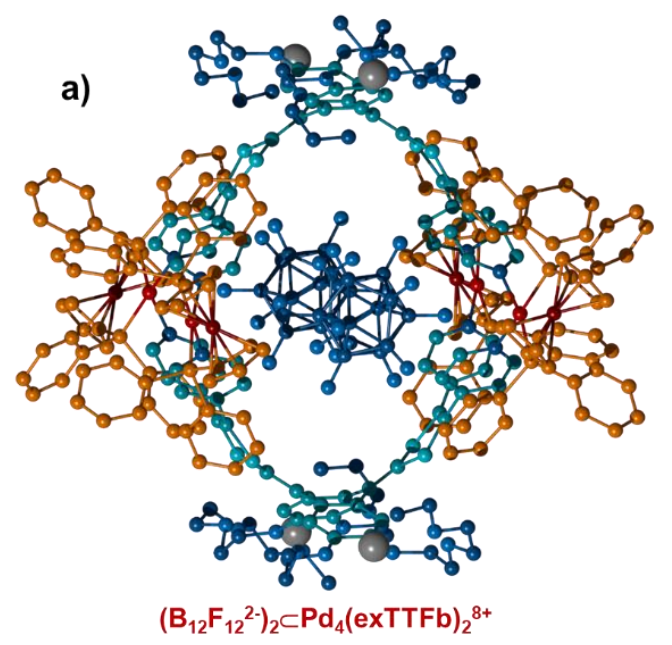

b)
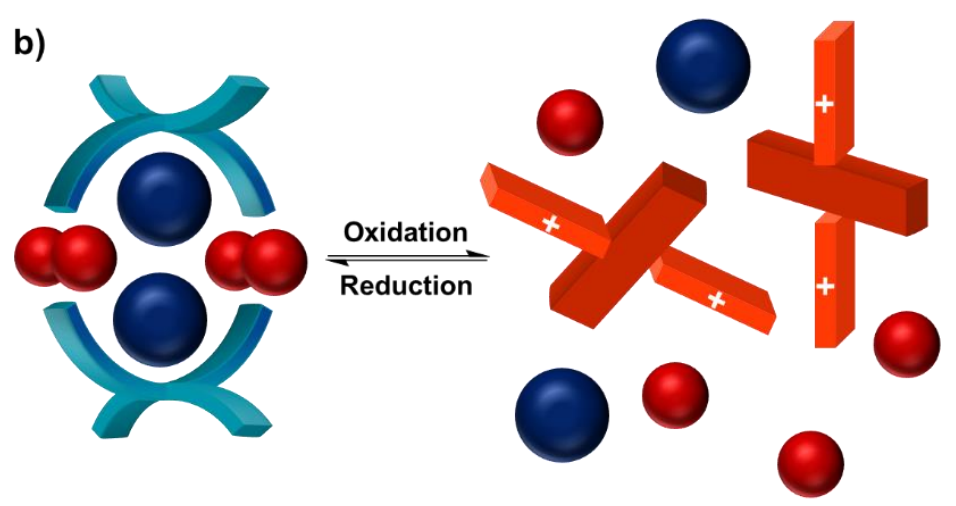

Figure 6. (a) X-Ray crystal structure of the $\left(\mathrm{B}_{12} \mathrm{~F}_{12}{ }^{2-}\right)_{2} \subset \mathbf{P d}_{4}(\mathbf{e x T T F b})_{2}{ }^{8+}$; (b) Cartoon illustrating the reversible complexation/release process of $\mathrm{B}_{12} \mathrm{~F}_{12}{ }^{2-}$ guests from $\mathbf{P d} 4(\mathbf{e x T T F b}) \mathbf{2}^{\mathbf{8}^{+}}$upon oxidation/reduction. $^{2}$

Interestingly, the $\left(\mathrm{B}_{12} \mathrm{~F}_{12}{ }^{2-}\right)_{2} \subset \mathbf{P d} \mathbf{4}(\mathbf{e x T T F b})_{2}{ }^{8+}$ complex displays specific characteristics which could be used to realize a redox-controlled guest binding/release process: $i$ ) the affinity between the host and the guest is high, ii) the anionic guest is redox-silent and iii) the host-guest behavior can be monitored by ${ }^{1} \mathrm{H}$ and ${ }^{19} \mathrm{~F}$ NMR spctroscopy. Prior to this study, the empty $\mathbf{P d}_{4}(\mathbf{e x T T F b})_{2}{ }^{\mathbf{8}^{+}}$ cage was subjected to a chemical oxidation/reduction cycle. After addition of an oxidant (thianthrenium, $\mathrm{Th}^{\bullet+}$ ), three species were detected in the NMR solution. They were identified as the oxidized dicationic ligand $\mathbf{e x T T F b ^ { 2 + }}$, the $\mathrm{Pd}(\mathrm{dppf})(\mathrm{OTf})_{2}$ complex and the neutral thianthrene generated during the oxidation process. This result clearly demonstrates that the $\mathbf{P d} \mathbf{d}_{\mathbf{4}}\left(\mathbf{e x T T F b} \mathbf{2}^{\mathbf{8}^{+}}\right.$ cage is disassembled through oxidation of both exTTF constituents. This is explained by the combination of two effects: $i$ ) the drastic conformational change that accompanies oxidation of the 
exTTF-based ligand and, in parallel, ii) the strong electron-deficient character of $\mathbf{e x T T F b}{ }^{2+}$ units, which decreases the sigma-donor ability of the pyridine units. Remarkably, the addition of a chemical reductant (tetrakis(dimethylamino)ethylene, TDAE) leads to the reassembly to the initial $\mathbf{P d}_{4}(\mathbf{e x T T F b})_{2}{ }^{8+}$ cage, reflecting the reversibility of the process. The same oxidation/reduction cycle was applied to the $\left(\mathrm{B}_{12} \mathrm{~F}_{12}{ }^{2-}\right)_{2} \subset \mathbf{P d}_{4}(\mathbf{e x T T F b})_{2}{ }^{8+}$ complex, with the aim of redox-controlling the release/complexation of the guests. The addition of the chemical oxidant resulted in the disappearance of the characteristic ${ }^{19} \mathrm{~F}$ NMR signals of the encapsulated $\mathrm{B}_{12} \mathrm{~F}_{12}{ }^{2-}$ anions in favor of a unique signal at higher field, attributed to the free anions in solution. This was confirmed by a DOSY NMR analysis. Importantly, the subsequent reduction leads to the spontaneous reformation of the host/guest complex (Figure 6b). The proof-of-concept that a guest can be bound and released on-demand in a reversible way, using a self-assembled cage and a redox stimulus, was demonstrated here for the first time. ${ }^{2}$

An important further challenge lies on the extension of this approach to neutral guests. One has to keep in mind that self-assembled structures constructed under coordination-assistance mostly correspond to positively charged species which therefore, as illustrated above with the polycationic cage $\mathbf{P d} 4(\mathbf{e x T T F b}) \mathbf{2}^{8+}$, exhibit a good affinity for anionic species. Host-guest interactions are inherently weaker in the case of neutral guests since the polycationic character of the cages limits the kinetics and thermodynamies of their complexation whose inclusion in the cavity may, in addition, be hampered by competitive counter-anions which in some cases obstruct the cavity. ${ }^{95,96}$ On this basis and in order to bind more efficiently neutral guests, the synthesis of neutral metallaassembled receptors appears a promising approach. The latter can be notably synthesized either by the reaction of an anionic ligand (typically bearing carboxylate groups) with a metal cation, ${ }^{97}$ or by reaction of a neutral ligand with a neutral metal precursor. ${ }^{95}$ The ability of neutral receptors to 
bind neutral guests has already been described, ${ }^{95}$ but few is known to quantitatively qualify this association by comparison with charged analogues.

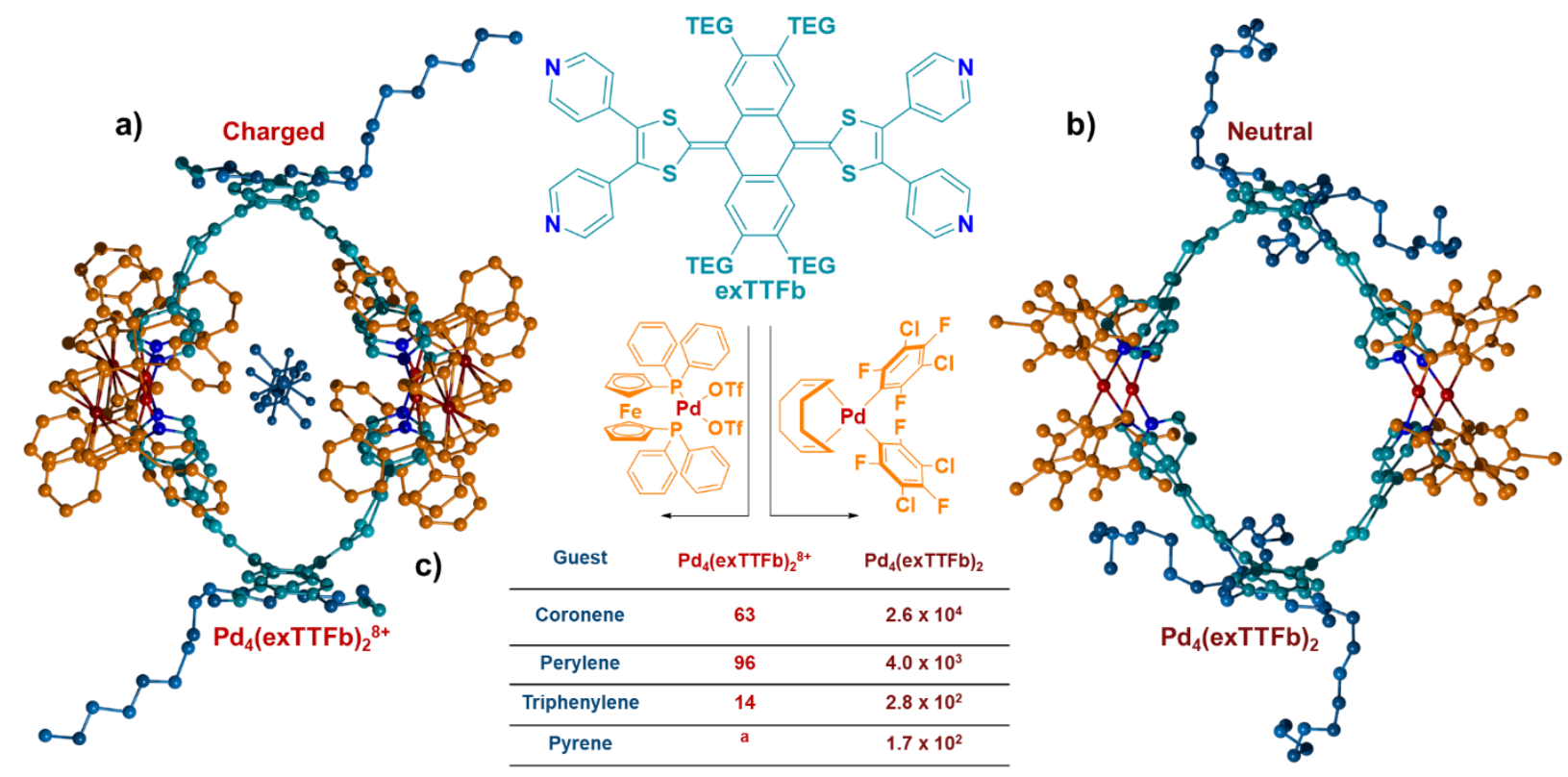

Figure 7. Synthesis of charged and neutral cages (a) $\mathbf{P d}_{4}(\mathbf{e x T T F b}) \mathbf{2}^{8+}$ and (b) $\mathbf{P d} 4 \mathbf{4}(\mathbf{e x T T F b}) 2$, and the corresponding crystal structures; (c) Calculated binding constants $\mathrm{K}_{\mathrm{a}}$ of both cages with planar polyaromatic guest in $\mathrm{CD}_{3} \mathrm{NO}_{2} / \mathrm{CDCl}_{3}(1 / 1) .{ }^{98}$

We therefore synthetized two neutral analogs of cage $\mathbf{P d} 4(\mathbf{e x T T F b}) 2^{\mathbf{8}^{+}} \cdot{ }^{98}$ Reaction of ligand exTTFb with the square-planar cis-Pd(dctfb $)_{2}(\operatorname{cod})$ precursors $(\mathrm{dctfb}=$ dichlorotrifluorobenzene, cod $=$ cyclooctadiene $)$ afforded the neutral $\mathbf{P d}_{4}(\mathbf{e x T T F b})_{2}$ container. An X-ray crystallography analysis (Figure 7b) revealed that the ovoid cavity of $\mathbf{P d} 4(\mathbf{e x T T F b})_{2}$ is similar in shape and dimensions to the octacationic one ( $15 \AA$ x $13 \AA$, and $15.5 \AA$ x $11.5 \AA$ respectively). Therefore, this neutral cage provides a unique opportunity for comparing binding properties of neutral and octacationic receptors, notably when considering neutral guests. A key difference to consider between both cases lies in the presence of counter anions with the octacationic cage. Indeed, as seen in the crystal structure of $\mathbf{P d} 4(\mathbf{e x T T F b}) \mathbf{2}^{8+}$ (Figure 7a), two triflate anions clearly obstruct the 
cavity, which are prone to behave as competitive guests in the binding studies in solution. This comparative study was carried out by titration using DOSY NMR (Figure 7c). As expected, the neutral cage systematically shows a better affinity for planar aromatic guests than the octacationic one, illustrating the key role of counterions. In order to further study the binding ability of such neutral ovoid cages, we synthesized the more robust Pt(II) cage $\mathbf{P t}_{4}(\mathbf{e x T T F b})_{2}$. The latter exhibits similar binding properties as the $\mathrm{Pd}(\mathrm{II})$ one. Interestingly, crystals from both $\mathrm{Pd}(\mathrm{II})$ and $\mathrm{Pt}(\mathrm{II})$ complexes with coronene could be obtained (coronenecPd4(exTTFb)2 and coronene $\left.\subset \mathbf{P t}_{4}(\mathbf{e x T T F b})_{2}\right)$ and show very similar geometric characteristics (Figure 8a). In both cases, intermolecular distances as short as $2.6 \AA$ are observed between the host cavity (pyridines $\beta$ protons) and the coronene mean plane, leading to a significant elongation of the ovoid cavity with respect to the empty cages. Hence the size of the cavity evolves from $15 \AA$ x $13 \AA$ for the empty cage to $16 \AA$ x $10.5 \AA$ after coronene complexation, reflecting a surprisingly high flexibility of the cavity.
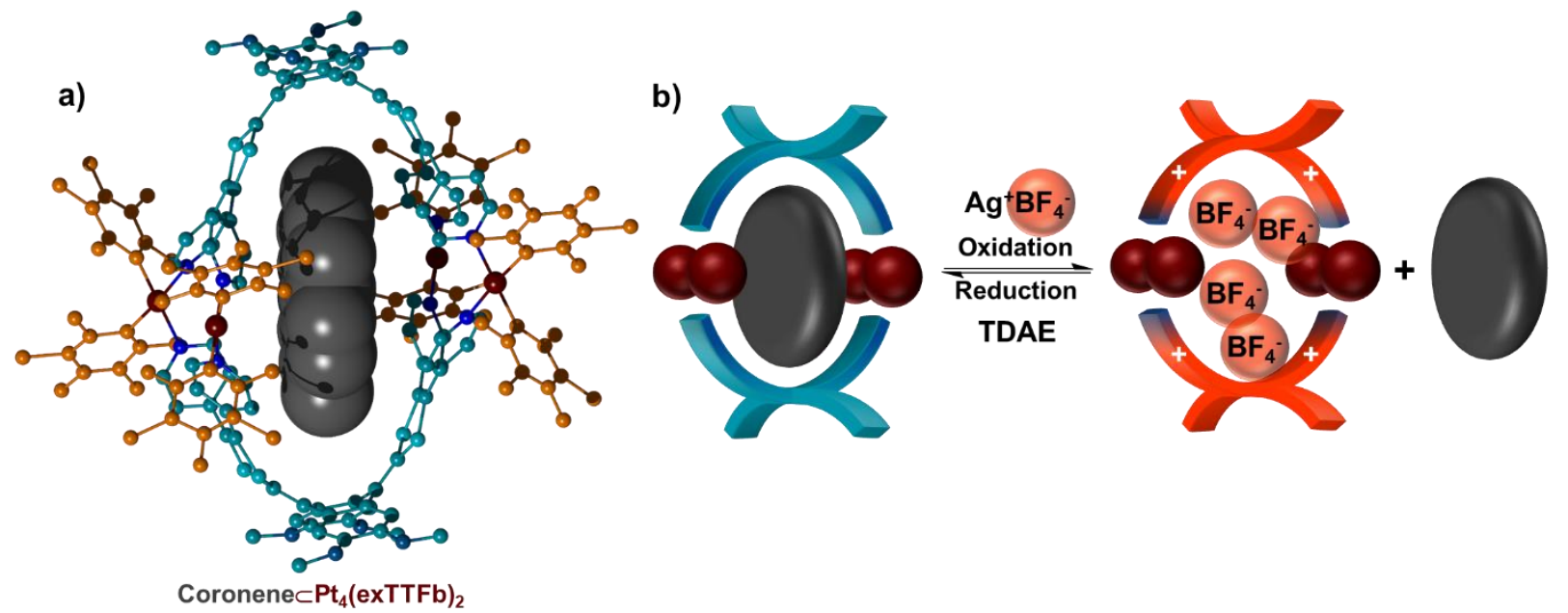

Figure 8. (a) X-Ray crystal structure of the coronenecPt4(exTTFb)2 complex; (b) Cartoon illustrating the guest exchange occurring upon oxidation/reduction of complex coronene $\subset \mathbf{P t}_{\mathbf{4}}(\mathbf{e x T T F b})_{2}{ }^{3}$ 

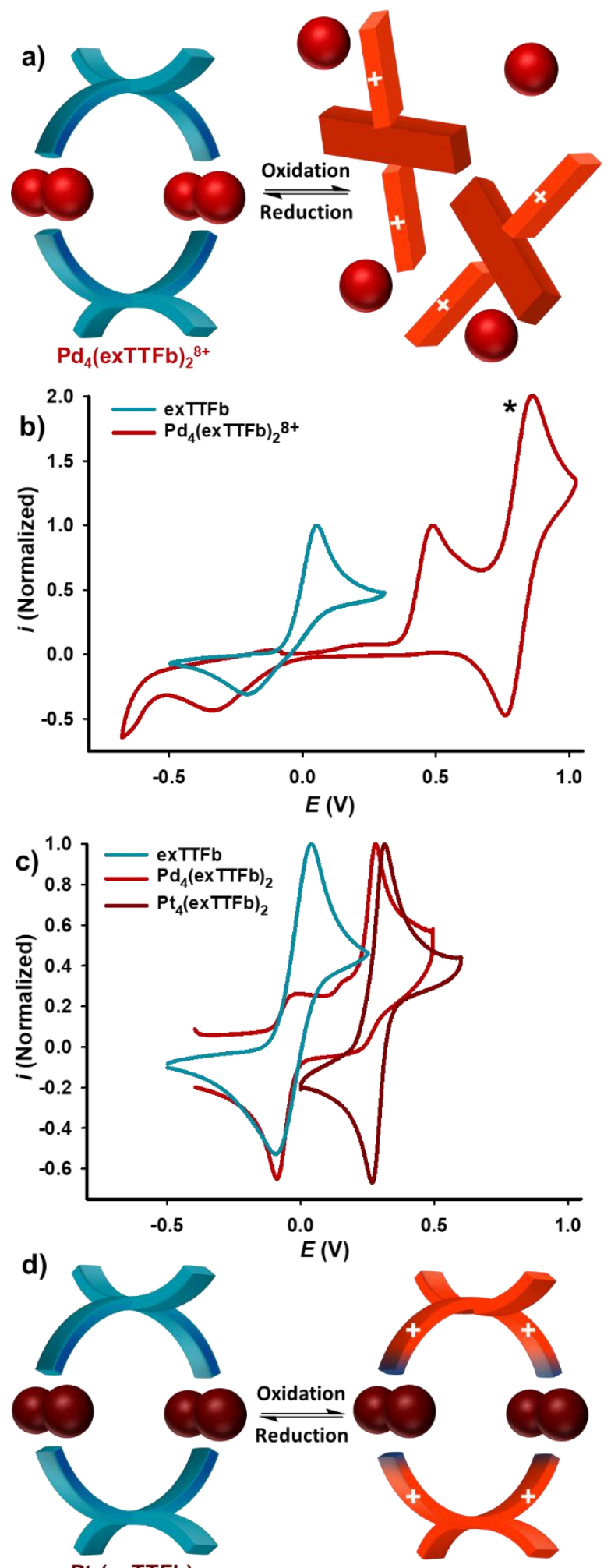

$\mathrm{Pt}_{4}(\mathrm{exTTFb})_{2}$ 
Figure 9. (a) Cartoon illustrating the reversible disassembling of $\mathbf{P d}_{\mathbf{4}}(\mathbf{e x T T F b})_{2}{ }^{\mathbf{8}^{+}}$upon oxidation/reduction; ${ }^{2}$ (b) Normalized cyclic voltammograms of ligand exTTFb and cage $\operatorname{Pd}_{4}(\mathbf{e x T T F b})_{2}{ }^{8+}\left(c=0.5 \mathrm{mM}, \mathrm{CH}_{3} \mathrm{CN}, 0.1 \mathrm{M} \mathrm{nBu}_{4} \mathrm{NPF}_{6}, 100 \mathrm{mV} \cdot \mathrm{s}^{-1}, \mathrm{~V}\right.$ vs FcH/FcH $\left.{ }^{+}\right),{ }^{*}$ this wave corresponds to the reversible oxidation of the ferrocenyl coligands; (c) Normalized cyclic voltammograms of ligand exTTFb and neutral cages $\left(\mathbf{P d}_{4}(\mathbf{e x T T F b})_{2}\right.$ and $\left.\mathbf{P t}_{\mathbf{4}}(\mathbf{e x T T F b})_{2}\right)(c=0.1$ $\mathrm{mM}, \mathrm{CH}_{2} \mathrm{Cl}_{2} / \mathrm{CH}_{3} \mathrm{CN}$ 1/1, $0.1 \mathrm{M} \mathrm{nBu}_{4} \mathrm{NPF}_{6}, 100 \mathrm{mV} \cdot \mathrm{s}^{-1}, \mathrm{~V}$ vs FcH/FcH ${ }^{+}$); (d) Cartoon illustrating the behavior of neutral cage $\mathbf{P t} 4(\mathbf{e x T T F b})_{2}$ upon oxidation/reduction. ${ }^{3}$

The electrochemical properties of charged $\mathbf{P d} 4(\mathbf{e x T T F b}) 2^{8+}$ and of both neutral cages (Pt4(exTTFb)2, Pt4(exTTFb)2) were investigated by cyclic voltammetry (Figure 9). As expected from metal coordination, oxidation of exTTF moieties occurs at a higher potential for the three containers when compared to the starting exTTFb ligand (Figures 9b,c). As mentioned above, oxidation of Pd4(exTTFb) ${ }^{8+}$ leads to the disassembly of the self-assembled structure and to the concomitant release of the oxidized ligand in solution (Figure 9a). This behavior is reflected in the cyclic voltammogram by a reduction process occurring at potential close to that of exTTFb(Figure 9b). A similar electrochemical behavior is observed for the neutral palladium Pd4(exTTFb)2 container (Figure 9c), illustrating here again occurrence of a disassembly process upon oxidation. The neutral platinum homologous $\mathbf{P t}_{4}(\mathbf{e x T T F b})_{2}$ exhibits a strikingly different electrochemical behavior (Figure 9c). In this case, a quasi-reversible oxidation wave is observed, which suggests the absence of any conformational change of the exTTF core upon oxidation. This difference with Pd4(exTTFb)2 is attributed to the higher energy of the pyridine to metal coordination bonds in the case of platinum vs palladium, which prevents the disassembly from occuring (Figure 9d). This hypothesis was confirmed by a chemical oxidation/reduction sequence $\left(\mathrm{AgBF}_{4} / \mathrm{TDAE}\right)$ monitored 
by ${ }^{1} \mathrm{H}$ NMR, DOSY NMR and FTICR-HRMS measurements, which also demonstrates that the process is reversible. Such behavior, without cage disassembling, appears particularly promising. Therefore, a step further lies on the exploration of this specific behavior in the case of the corresponding host-guest complex (coronene $\left.\subset \mathbf{P t}_{4}(\mathbf{e x T T F b})_{2}\right)$. The same experiments, supplemented by spectroelectrochemical measurements, demonstrate unambiguously the quantitative redox-controlled binding/release ability of $\mathbf{P t}_{4}(\mathbf{e x T T F b})_{2}$ for coronene. In addition, DFT calculations establish that when the cavity is oxidized from a 0 to a $4+$ state, an original change occurs in the interaction mode between the host and the guest. While coronene is strongly bound when the cage is neutral, oxidation of the latter to a tetracationic state is accompanied by the migration of counter anions to inside the cavity. As a consequence, the coronene guest is displaced to the solution, giving rise to a guest exchange process. On this basis, this robust receptor based on the combination of a Pt(II) complex and a redox-active ligand, affords the first example of a redox-controlled release of a neutral guest without disassembling (Figure 8b). ${ }^{3}$

\section{DTF-based cages and tweezers}

The planar and electron-rich 9-(1,3-dithiol-2-ylidene)-fluorene (DTF) unit is known to undergo a reversible one-electron oxidation at low potential, to generate a radical-cation species. ${ }^{99,100} \mathrm{On}$ the other hand, a new class of $\mathrm{M}_{2} \mathrm{~L}_{4}$ metal driven self-assembled structures has emerged recently, which are built from the combination of so-called "banana-shaped" ligands and "naked" cations for which all coordination sites are available. ${ }^{101,102}$ On this basis, and given the suitable geometrical characteristics of the DTF scaffold, we designed ligand DTFa, which is then reacted with $\operatorname{Pd}\left(\mathrm{CH}_{3} \mathrm{CN}\right)_{4}\left(\mathrm{BF}_{4}\right)_{2}$ to afford the $\mathbf{P d}_{2}(\mathbf{D T F a}) 4^{4+}$ structure (Figure 10a). ${ }^{103}$ An X-Ray crystallography analysis could be carried out from this new three-dimensional structure, and a 
cavity of $600 \AA^{3}$ was determined; nevertheless, no evidence of guest binding could be demonstrated in solution. The electrochemical behavior of cage $\mathbf{P d}_{2}(\mathbf{D T F a}) 4^{4+}$ was studied by cyclic voltammetry. One reversible process is observed at $E^{o x}=0.62 \mathrm{~V} \mathrm{vs} \mathrm{FcH} / \mathrm{FcH}^{+}$, a value which is slightly higher than the one observed for ligand DTFa, as expected from coordination to the metal (Figure 10c). This behavior indicates that all DTF units behave independently presumably because of the rigidity of the system which does not allow any electronic interaction to occur between the neighboring electron-active units.

a)
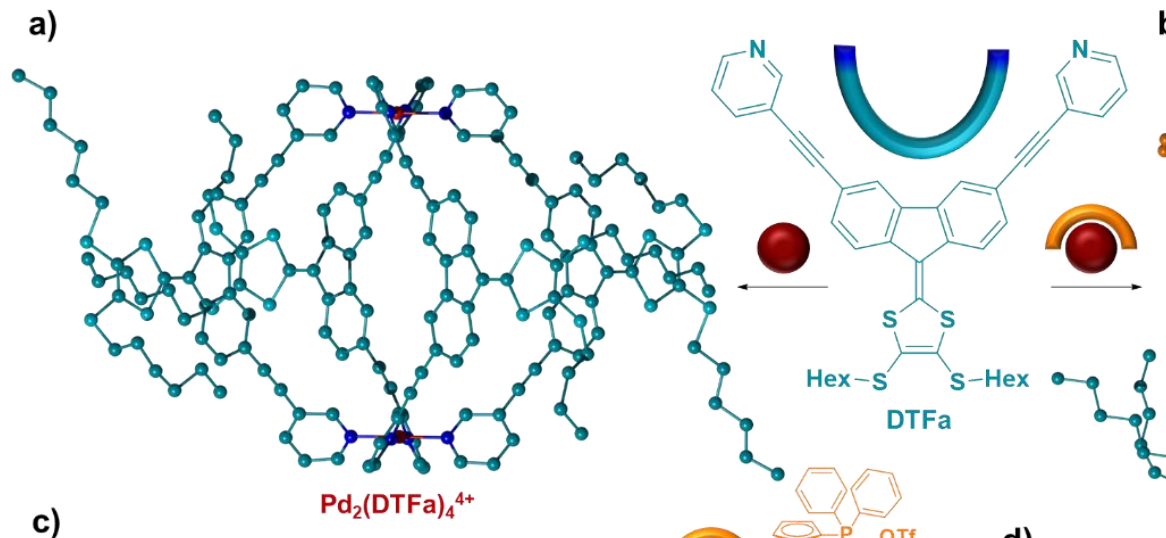

b)
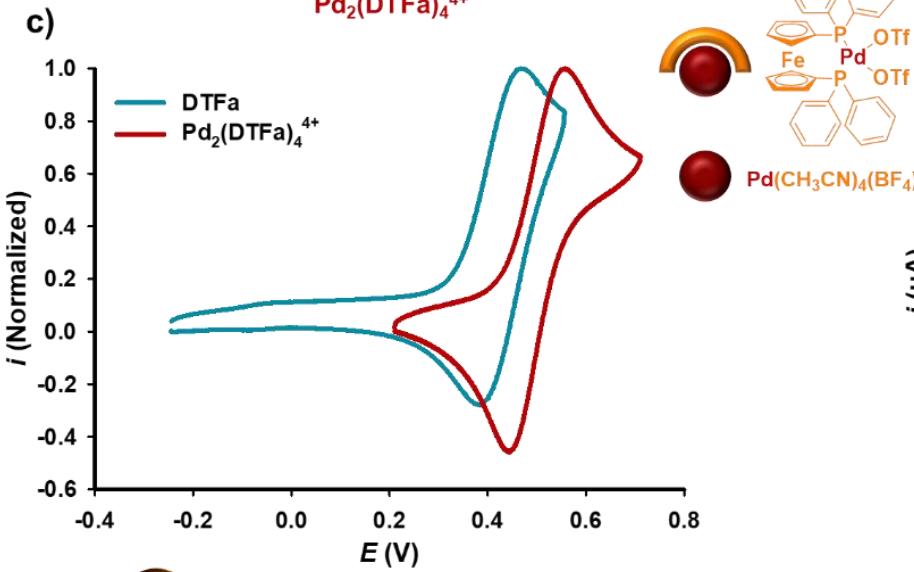

d)

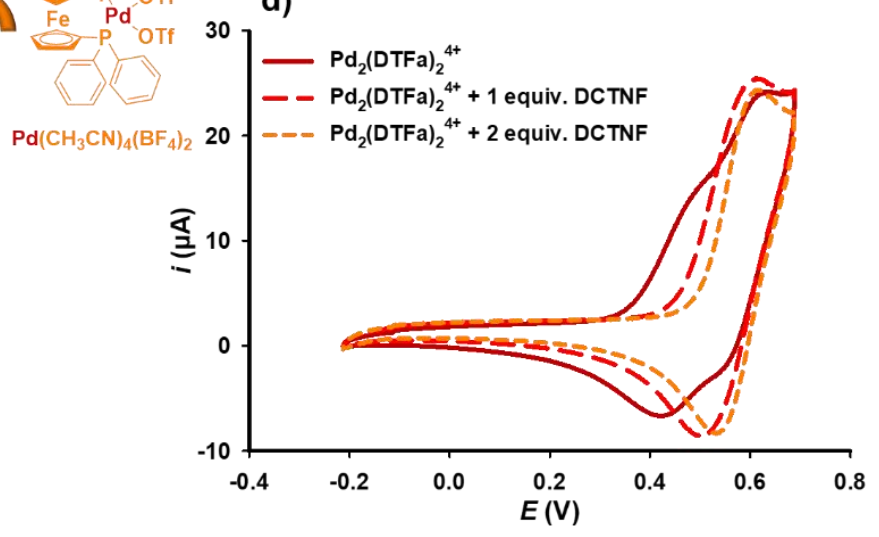

e)
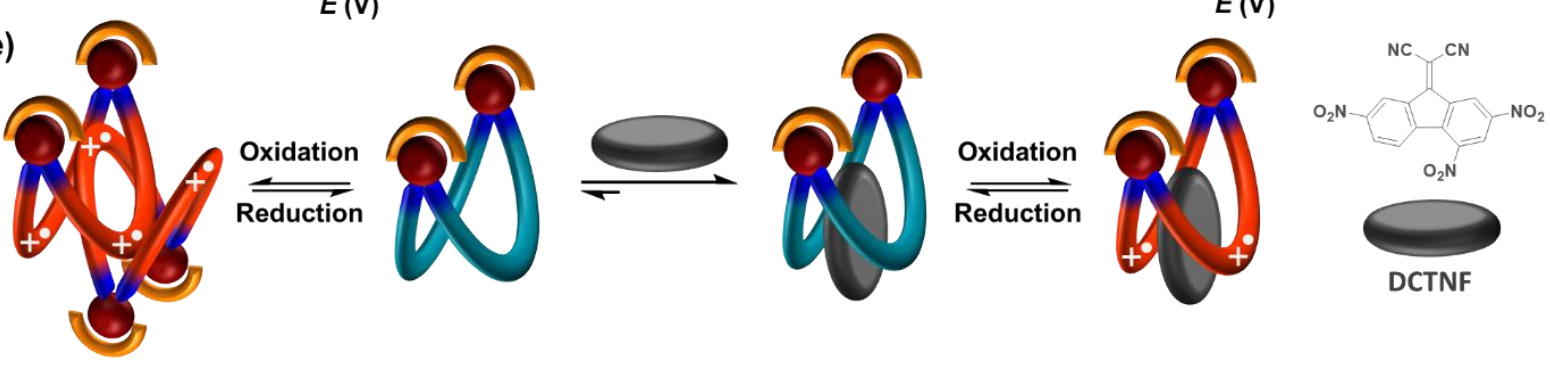
Figure 10. (a) Synthesis of cage $\mathbf{P d}_{2}(\mathbf{D T F a}) 4^{4+}$ and corresponding crystal structure ${ }^{103}$ (b) Synthesis of clip Pd2(DTFa) $\mathbf{2}^{\mathbf{4}}$ and corresponding molecular force field (MM+) model; ${ }^{104}$ (c) Normalized cyclic voltammograms of ligand DTFa $\left(c=1 \mathrm{mM}\right.$ in $\mathrm{CH}_{3} \mathrm{CN} / \mathrm{CH}_{2} \mathrm{Cl}_{2} 1 / 1,0.1 \mathrm{M}$ $\mathrm{nBu}_{4} \mathrm{NPF}_{6}, 50 \mathrm{mV} \cdot \mathrm{s}^{-1}, \mathrm{~V}$ vs FcH/FcH $\left.{ }^{+}\right)$and cage $\mathbf{P d}_{2}(\mathbf{D T F a})_{4}{ }^{4+}\left(c=0.5 \mathrm{mM}\right.$ in $\mathrm{CH}_{2} \mathrm{Cl}_{2}, 0.05 \mathrm{M}$ $\mathrm{NaBArF}, 50 \mathrm{mV} \cdot \mathrm{s}^{-1}, \mathrm{~V}$ vs $\left.\mathrm{FcH} / \mathrm{FcH}^{+}\right)$; (d) Cyclic voltammograms of clip $\mathbf{P d}_{\mathbf{2}}(\mathbf{D T F a})_{2}{ }^{\mathbf{4}}(c=1$ $\mathrm{mM}$ ) in the presence of DCTNF (in $\mathrm{CH}_{3} \mathrm{CN} / \mathrm{CH}_{2} \mathrm{Cl}_{2} 1 / 1,0.1 \mathrm{M} \mathrm{nBu} 4 \mathrm{NPF}_{6}, 100 \mathrm{mV} \cdot \mathrm{s}^{-1}, \mathrm{~V}$ vs $\mathrm{FcH} / \mathrm{FcH}^{+}$); (e) Cartoon illustrating the redox behavior and binding properties of $\mathbf{P d}_{2}(\mathbf{D T F a})_{2}{ }^{4+}$.

The same ligand, DTFa, reacts with the cis-blocked Pd(dppf)(OTf $)_{2}$ complex to afford the clip compound Pd2 $\mathbf{P}(\mathrm{DTFa})_{2}{ }^{4+}$, whose structure is characterized by an intramolecular S $\cdots \mathrm{S}$ distance of ca $8.5 \AA$ A between both DTF tips (Figure 10b). ${ }^{104}$ The corresponding cyclic voltammogram exhibits two reversible oxidation processes at $E_{1}{ }^{\mathrm{ox}}=0.49 \mathrm{~V}$ and $E_{2}{ }^{\mathrm{ox}}=0.63 \mathrm{~V} v s \mathrm{FcH} / \mathrm{FcH}^{+}$, indicating that both DTF tips interact (Figure 10d). As already reported for TTF-based molecular tweezers, ${ }^{105}$ such a splitting of the first redox wave can be ascribed to the successive formation of mixedvalence and $\pi$-dimer species. The inter tips distance of $8.5 \AA$ is appropriate to host planar species, including self-intercalation of the molecular clip. The latter point is confirmed by a concentration dependent experiment, which shows that the wave splitting disappears upon decreasing the concentration. This result confirms the self-dimerization of two molecular clips upon oxidation thanks to favorable radical pairing interactions. ${ }^{106-108}$ The latter constitutes a supramolecular interaction of particular interest that can be controlled through a redox stimulation as shown with the prototypal cases of tetrathiafulvalene ${ }^{109}$ or bipyridinium ${ }^{110}$ derivatives. We also studied the behavior of the electron-rich $\mathbf{P d}$ (DTFa)2 ${ }^{4+}$ cavity for complexing the electron-deficient 9dicyanomethylene-2,4,7-trinitrofluorene (DCTNF) $\pi$-acceptor molecule, a unit which is known to 
interact strongly with electron-rich derivatives. ${ }^{111}$ A UV-vis titration completed by a Job plot analysis revealed the formation of a 1:1 host-guest complex with an association constant of $\mathrm{K}_{\mathrm{a}}=$ $7.8( \pm 0.9) \times 10^{5}$ in $\mathrm{CH}_{2} \mathrm{Cl}_{2}$ (Figure 10e). This recognition process was followed by cyclic voltammetry experiments (Figure 10d). Progressive addition of DCTNF to a solution of $\mathbf{P d}_{2}(\mathbf{D T F a})_{2}{ }^{4+}$ results in disappearance of the wave splitting, indicating that the intercalation of DCTNF prevents formation of the dimeric oxidized structure (Figure 10e). ${ }^{104}$

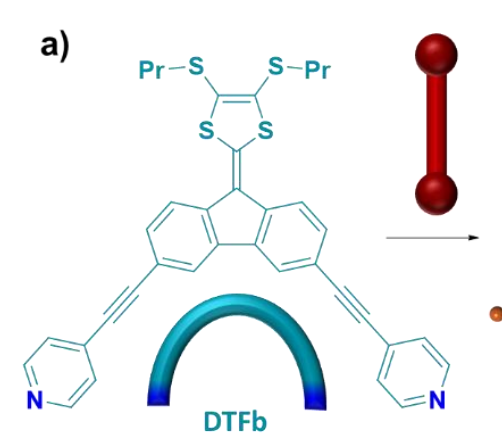

b)

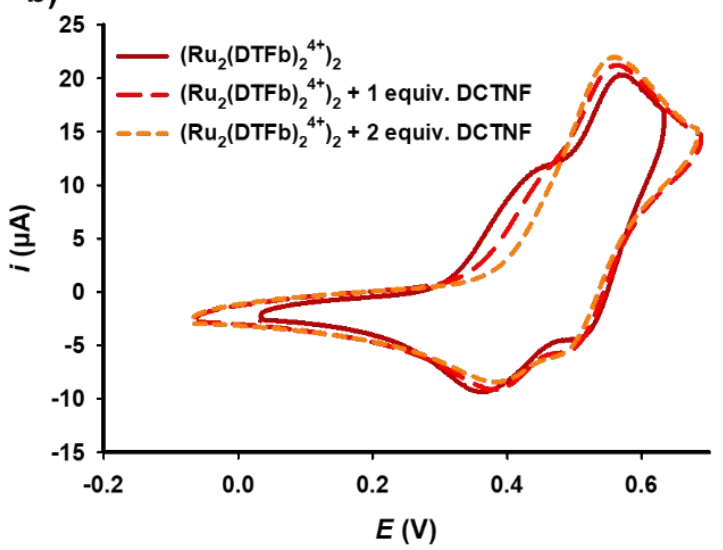

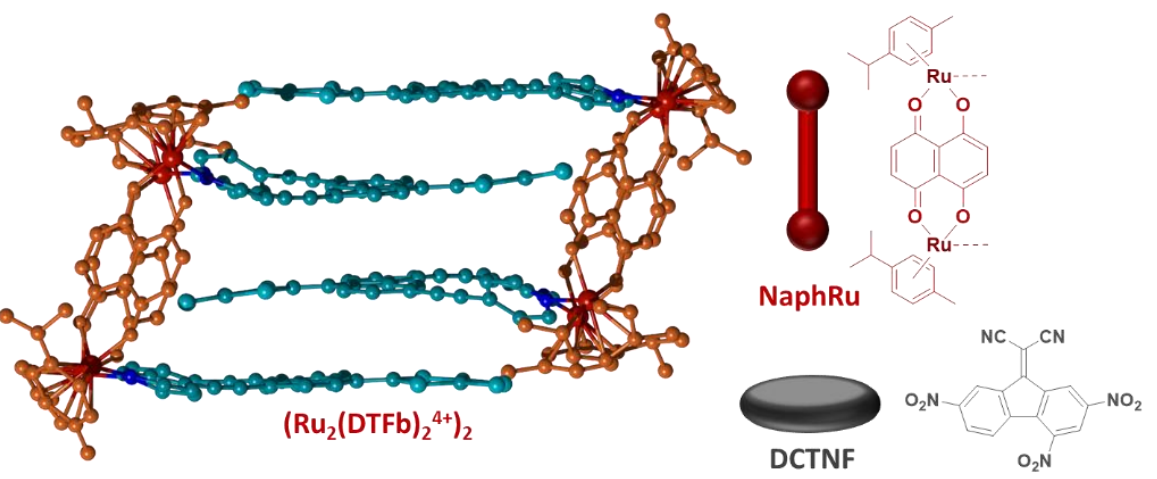

c)
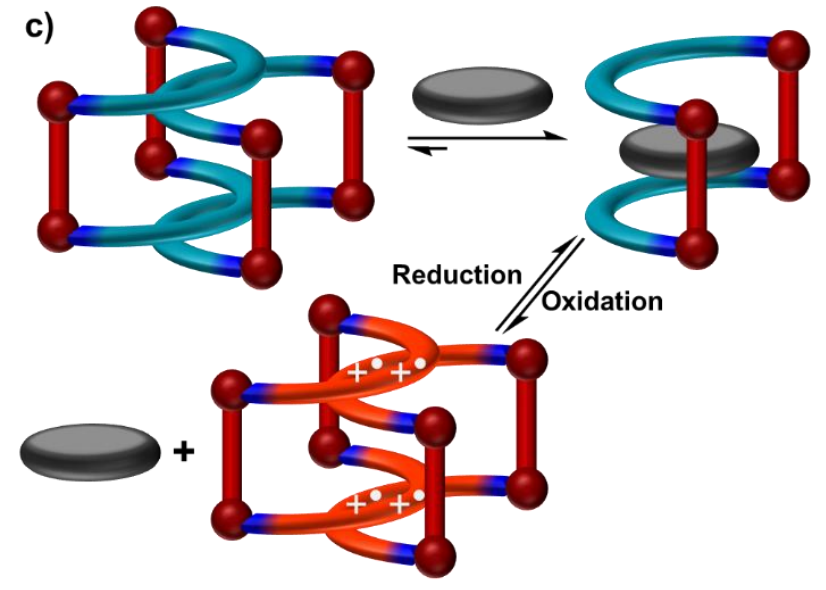

Figure 11. (a) Synthesis of self-assembled dimeric tweezer $\left(\mathbf{R u} 2(\mathbf{D T F b}) \mathbf{2}^{\mathbf{4 +}}\right)_{\mathbf{2}}$ and corresponding crystal structure; (b) Cyclic voltammograms of clip $\left(\mathbf{R u}_{2}(\mathbf{D T F b})_{2} \mathbf{2}^{4+}\right)_{\mathbf{2}}(c=1 \mathrm{mM})$ without, and in presence of DCTNF (in $\mathrm{CH}_{3} \mathrm{CN}, 0.1 \mathrm{M} \mathrm{nBu}_{4} \mathrm{NPF}_{6}, 100 \mathrm{mV} \cdot \mathrm{s}^{-1}$, V vs $\mathrm{FcH} / \mathrm{FcH}^{+}$); (c) Cartoon illustrating the encapsulation properties of $\mathbf{R} \mathbf{u}_{2}(\mathbf{D T F b}) 2^{\mathbf{4}^{+}}$as well as the DCTNF release process from DCTNF $\subset \mathbf{R u} \mathbf{u}_{2}(\mathbf{D T F b}) \mathbf{2}^{4+}$, with the concomitant formation of the oxidized dimer $\left(\operatorname{Ru} 2(\mathrm{DTFb}) \mathbf{2}^{\mathbf{4}^{+}}\right) \mathbf{2}^{\mathbf{4 ( + + )}}$. $^{4}$ 
DTFb, a positional isomer of DTFa, was designed to promote the formation of alternative selfassembled species (Figure 11). ${ }^{4}$ To favor guest inclusion of planar species, a distance of $\mathrm{ca}$ 7-8 $\AA$ is usually required between both parallel tips in molecular tweezers. The bis-metallic ruthenium complex NaphRu (Figure 1) matches with this prerequisite, since it displays two available coordination sites with parallel orientations and an intramolecular Ru-Ru distance of $8.4 \AA$. The ${ }^{1} \mathrm{H}$ NMR spectrum resulting from the reaction of DTFb with NaphRu exhibits a splitting of the signals, notably in the fluorenyl region, which is assigned to an intercalated dimeric structure driven by $\pi-\pi$ interactions. The calculated hydrodynamic radius of $19 \AA$ as well as FTICR-HRMS measurements confirm the formation of the supramolecular dimer $\left(\mathbf{R} \mathbf{u}_{2}(\mathbf{D T F b}) \mathbf{2}^{4+}\right)_{2}$. An X-Ray crystallography analysis reveals that two tweezer molecules are interdigitated and stabilized by $\pi$ $\pi$ interactions with intermolecular distances of $c a 3.5 \AA$ between two tips (Figure 11a,c). The stability of the dimeric supramolecular structure was investigated by concentration dependent NMR experiments and a dimerization constant $\mathrm{K}_{\mathrm{dim}}=4.4( \pm 0.2) \times 10^{3}$ in $\mathrm{MeOH}$ was calculated. The spontaneous formation of an intercalated structure also indicates the ability of tweezer $\mathbf{R} \mathbf{u}_{2}(\mathbf{D T F b}) \mathbf{2}^{4+}$ to bind one planar guest. Therefore, the stability of the dimeric structure $\left(\mathrm{Ru}_{2}(\mathrm{DTFb}) \mathbf{2}^{4+}\right)_{2}$ was further studied in presence of the electron-deficient DCTNF unit. NMR and FTICR-HRMS experiments supplemented by UV-Vis titrations unambiguously demonstrate the formation of the DCTNF $\subset \mathbf{R u} \mathbf{u}_{2}(\mathbf{D T F b}) \mathbf{2}^{\mathbf{4 +}}$ inclusion complex, with a high association constant of $\mathrm{K}_{\mathrm{a}}=2.4( \pm 0.2) \times 10^{5}$ in $\mathrm{MeOH}$. The electronic properties of $\left(\mathbf{R u} \mathbf{u}_{2}(\mathbf{D T F b})_{2}{ }^{4+}\right)_{2}$ were studied by cyclic voltammetry (Figure 11b). This dimeric structure shows a reversible and split oxidation wave, ascribed to the formation of oxidized mixed-valence and $\pi$-dimer species. ${ }^{105}$ As for molecular clip $\mathbf{P d}_{\mathbf{2}}(\mathbf{D T F b})_{2}{ }^{\mathbf{4 +}}$ described above, addition of the electron-deficient guest leads to the 
disappearance of the wave splitting, while displacing the equilibrium toward formation of the hostguest complex DCTNF $\subset \mathbf{R} \mathbf{u}_{2}(\mathbf{D T F b})_{2}{ }^{\mathbf{4 +}}$ (Figure 11b). Remarkably, oxidation of the latter affords the oxidized $\left(\mathbf{R u} \mathbf{2}_{\mathbf{2}}(\mathbf{D T F b}) \mathbf{2}^{\mathbf{4 +}} \mathbf{2}^{\mathbf{4 ( + )}}\right.$ dimeric structure, whose high stability is confirmed by simulated voltammograms, with the concomitant releasing of DCTNF (Figure 11c), thereby illustrating an original mode of redox-driven guest delivering. ${ }^{4}$

\section{CONCLUSION}

This Account summarizes achievements led in Angers related to the development of redox-active coordination polygons and cages. Those discrete supramolecular assemblies are prepared by the metal-driven self-assembly strategy, and we focused our interest on host systems sensitive to a redox stimulus. The highly versatile character of this strategy allowed us to obtain a large variety of host structures, featuring $\pi$-donating cavities made of electron-rich TTF derivatives. Those receptors, be they neutral or polycationic, can complex various types of molecular guest within their cavities. Since they are readily oxidized, a key feature relies on the possibility to tune reversibly the charge state of the cavity upon application of an electrical potential or addition of a chemical oxidant. We demonstrate that such a control over the cavity charge provides an answer to the challenging issue of the delivering of a guest molecule from a host-guest complex. We notably establish a proof-of-concept related to the on-demand release of a given guest based on a redox-stimulus, through three different processes: 1) disassembling of the host structure thanks to a drastic conformational change of the cavity walls on oxidation, 2) guest-exchange with anions upon generating of a positively charged cavity, and 3) self-dimerization of a tweezer molecule driven by radical pairing. Importantly, all those processes are reversible, i.e. the initial host-guest complex is restored upon chemical or electrochemical reduction. On this basis and given the wide 
range of application fields which are concerned, it is hoped that this Account will aid in the development of new redox-active metalla-assemblies designed for guest delivering.

\section{AUTHOR INFORMATION}

\section{Corresponding Authors}

Sébastien Goeb - Univ Angers, CNRS, MOLTECH-ANJOU, 2 bd Lavoisier, F-49000 Angers, France; (D) orcid.org/0000-0003-2470-0768; Email: sebastien.goeb@univ-angers.fr

Marc Sallé - Univ Angers, CNRS, MOLTECH-ANJOU, 2 bd Lavoisier, F-49000 Angers, France;

D orcid.org/0000-0003-4601-6334; Email: marc.salle@,univ-angers.fr

\section{Author Contributions}

The manuscript was written through contributions of both authors. Both authors have given approval to the final version of the manuscript.

\section{Biographies}

Sebastien Goeb obtained his $\mathrm{PhD}$ degree in Organic Chemistry in 2006 under the supervision of Drs Raymond Ziessel and Antoinette De Nicola. He then carried out two successive one year postdoctoral stays respectively with Prof. Felix N. Castellano at the University of Bowling Green (USA) and with Dr Jean-Luc Parrain at the Institut des Sciences Moléculaires de Marseille (France). He became Chargé de Recherche CNRS in the laboratory MOLTECH-Anjou in 2008. He was awarded in 2020 the young researcher price from the Supramolecular group of the Société Chimique de France (SCF). His research activity focuses on the design of molecular architectures built by coordination self-assembly. In particular, he designs redox stimulable molecular hosts capable of modulating their complexation properties. 
Marc Sallé received his Ph.D. degree in organic chemistry from the University of Angers in 1991 under the supervision of Professor Alain Gorgues. After a postdoctoral stay with Professor Martin R. Bryce at the University of Durham (UK), he became Assistant Professor at the University of Angers, where he was promoted to a Professor in 1998 . He was awarded the Dina Surdin prize and junior membership of the Institut Universitaire de France (IUF) and has been nominated Distinguished Senior member of the Société Chimique de France. His research interests concern molecular materials and supramolecular chemistry associated with electro(photo)-active molecular systems.

\section{ACKNOWLEDGMENT}

We gratefully acknowledge financial support from the ANR (ANR-14-CE08-0001 BOMBER), the University of Angers and French Embassy in Kiev (Ukr) for providing PhD grants. We are particularly indebted to the high quality $\mathrm{PhD}$ and post-doc fellows who contributed to this project (Jean-Yves Balandier, Sébastien Bivaud, Marcos Chas, Vincent Croué, Maksym Dekhtiarenko, Paul I. Dron, Serhii Krykun, Gyorgy Szaloki, Vaishali Vajpayee). We also warmly acknowledge all the partners who collaborated on this project, be they members of MOLTECH-Anjou (Olivier Alévêque, Magali Allain, David Canevet, Ingrid Freuze, Eric Levillain, Cécile Mézière, Yohann Morille, Benjamin Siegler) or outside collaborators (Juan Aragó, Frédéric Aubriet, Vincent Carré, Enrique Ortí, Bruno Therrien, Zoia Voitenko).

\section{REFERENCES}

(1) Bivaud, S.; Balandier, J. Y.; Chas, M.; Allain, M.; Goeb, S.; Sallé, M. A MetalDirected Self-Assembled Electroactive Cage with Bis(pyrrolo)tetrathiafulvalene (BPTTF) Side Walls. J. Am. Chem. Soc. 2012, 134, 11968-11970. 
(2) Croué, V.; Goeb, S.; Szalóki, G.; Allain, M.; Sallé, M. Reversible Guest Uptake/Release by Redox-Controlled Assembly/Disassembly of a Coordination Cage. Angew. Chem. Int. Ed. 2016, 55, 1746-1750.

(3) Szalóki, G.; Croué, V.; Carré, V.; Aubriet, F.; Alévêque, O.; Levillain, E.; Allain, M.; Arago, J.; Orti, E.; Goeb, S.; Sallé, M. Controlling the Host-Guest Interaction Mode through a Redox Stimulus. Angew. Chem. Int. Ed. 2017, 56, 16272-16276.

(4) Krykun, S.; Dekhtiarenko, M.; Canevet, D.; Carré, V.; Aubriet, F.; Levillain, E.; Allain, M.; Voitenko, Z.; Sallé, M.; Goeb, S. Metalla-Assembled Electron-Rich Tweezers: Redox-Controlled Guest Release Through Supramolecular Dimerization. Angew. Chem. Int. Ed. 2020, 59, 716-720.

(5) Sun, Y.; Chen, C.; Liu, J.; Stang, P. J. Recent developments in the construction and applications of platinum-based metallacycles and metallacages via coordination. Chem. Soc. Rev. 2020, 49, 3889-3919.

(6) Li, B.; He, T.; Fan, Y.; Yuan, X.; Qiu, H.; Yin, S. Recent developments in the construction of metallacycle/metallacage-cored supramolecular polymers via hierarchical selfassembly. Chem. Commun. 2019, 55, 8036-8059.

(7) Wu, G.-Y.; Chen, L.-J.; Xu, L.; Zhao, X.-L.; Yang, H.-B. Construction of supramolecular hexagonal metallacycles via coordination-driven self-assembly: Structure, properties and application. Coord. Chem. Rev. 2018, 369, 39-75.

(8) Lu, Y.; Zhang, H.-N.; Jin, G.-X. Molecular Borromean Rings Based on HalfSandwich Organometallic Rectangles. Acc. Chem. Res. 2018, 51, 2148-2158.

(9) Pullen, S.; Clever, G. H. Mixed-Ligand Metal-Organic Frameworks and Heteroleptic Coordination Cages as Multifunctional Scaffolds - A Comparison. Acc. Chem. Res. 2018, 51, 3052-3064.

(10) Holloway, L. R.; Bogie, P. M.; Hooley, R. J. Controlled self-sorting in selfassembled cage complexes. Dalton Trans. 2017, 46, 14719-14723.

(11) Huang, S.-L.; Hor, T. S. A.; Jin, G.-X. Metallacyclic assembly of interlocked superstructures. Coord. Chem. Rev. 2017, 333, 1-26.

(12) Jing, X.; He, C.; Zhao, L.; Duan, C. Photochemical Properties of Host-Guest Supramolecular Systems with Structurally Confined Metal-Organic Capsules. Acc. Chem. Res. 2019, 52, 100-109.

(13) Fan, Q.-J.; Lin, Y.-J.; Hahn, F. E.; Jin, G.-X. Host-guest capability of a threedimensional heterometallic macrocycle. Dalton Trans. 2018, 47, 2240-2246.

(14) Fazio, E.; Haynes, C. J. E.; de la Torre, G.; Nitschke, J. R.; Torres, T. A giant $\mathrm{M}_{2} \mathrm{~L}_{3}$ metallo-organic helicate based on phthalocyanines as a host for electroactive molecules. Chem. Commun. 2018, 54, 2651-2654.

(15) Frischmann, P. D.; Kunz, V.; Würthner, F. Bright Fluorescence and Host-Guest Sensing with a Nanoscale $\mathrm{M}_{4} \mathrm{~L}_{6}$ Tetrahedron Accessed by Self-Assembly of Zinc-Imine Chelate Vertices and Perylene Bisimide Edges. Angew. Chem. Int. Ed. 2015, 54, 7285-7289.

(16) Govindarajan, R.; Nagarajaprakash, R.; Manimaran, B. Synthesis, Structural Characterization, and Host-Guest Studies of Aminoquinonato-Bridged Re(I) Supramolecular Rectangles. Inorg. Chem. 2015, 54, 10686-10694.

(17) Yamashina, M.; Sartin, M. M.; Sei, Y.; Akita, M.; Takeuchi, S.; Tahara, T.; Yoshizawa, M. Preparation of Highly Fluorescent Host-Guest Complexes with Tunable Color upon Encapsulation. J. Am. Chem. Soc. 2015, 137, 9266-9269. 
(18) Zhao, C.; Sun, Q.-F.; Hart-Cooper, W. M.; DiPasquale, A. G.; Toste, F. D.; Bergman, R. G.; Raymond, K. N. Chiral Amide Directed Assembly of a Diastereo- and Enantiopure Supramolecular Host and its Application to Enantioselective Catalysis of Neutral Substrates. J. Am. Chem. Soc. 2013, 135, 18802-18805.

(19) Rizzuto, F. J.; von Krbek, L. K. S.; Nitschke, J. R. Strategies for binding multiple guests in metal-organic cages. Nat. Rev. Chem. 2019, 3, 204-222.

(20) Riddell, I. A.; Hristova, Y. R.; Clegg, J. K.; Wood, C. S.; Breiner, B.; Nitschke, J. R. Five Discrete Multinuclear Metal-Organic Assemblies from One Ligand: Deciphering the Effects of Different Templates. J. Am. Chem. Soc. 2013.

(21) Brake, H.; Peresypkina, E.; Heindl, C.; Virovets, A. V.; Kremer, W.; Scheer, M. From nano-balls to nano-bowls. Chem. Sci. 2019, 10, 2940-2944.

(22) Peresypkina, E.; Virovets, A.; Scheer, M. Supramolecular Synthons: Will Giant Rigid Superspheres Do? Cryst. Growth Des. 2016, 16, 2335-2341.

(23) Smulders, M. M.; Riddell, I. A.; Browne, C.; Nitschke, J. R. Building on architectural principles for three-dimensional metallosupramolecular construction. Chem. Soc. Rev. 2013, 42, 1728-1754.

(24) Lankshear, M. D.; Beer, P. D. Strategic anion templation. Coord. Chem. Rev. 2006, 250, 3142-3160.

(25) Wezenberg, S. J. Light-switchable Metal-Organic Cages. Chem. Lett. 2020, 49, $609-615$.

(26) Chen, L.-J.; Yang, H.-B. Construction of Stimuli-Responsive Functional Materials via Hierarchical Self-Assembly Involving Coordination Interactions. Acc. Chem. Res. 2018, 51, 2699-2710.

(27) Diaz-Moscoso, A.; Ballester, P. Light-responsive molecular containers. Chem. Commun. 2017, 53, 4635-4652.

(28) Wang, W.; Wang, Y.-X.; Yang, H.-B. Supramolecular transformations within discrete coordination-driven supramolecular architectures. Chem. Soc. Rev. 2016, 45, 2656-2693.

(29) Qu, D.-H.; Wang, Q.-C.; Zhang, Q.-W.; Ma, X.; Tian, H. Photoresponsive HostGuest Functional Systems. Chem. Rev. 2015, 115, 7543-7588.

(30) Yoshizawa, M.; Catti, L. Bent Anthracene Dimers as Versatile Building Blocks for Supramolecular Capsules. Acc. Chem. Res. 2019, 52, 2392-2404.

(31) Kim, T. Y.; Vasdev, R. A. S.; Preston, D.; Crowley, J. D. Strategies for Reversible Guest Uptake and Release from Metallosupramolecular Architectures. Chem. Eur. J. 2018, 24, 14878-14890.

(32) Grommet, A. B.; Feller, M.; Klajn, R. Chemical reactivity under nanoconfinement. Nat. Nanotechnol. 2020, 15, 256-271.

(33) Jansze, S. M.; Cecot, G.; Severin, K. Reversible disassembly of metallasupramolecular structures mediated by a metastable-state photoacid. Chem. Sci. 2018, 9 , $4253-4257$.

(34) Han, M.; Michel, R.; He, B.; Chen, Y. S.; Stalke, D.; John, M.; Clever, G. H. Light-triggered guest uptake and release by a photochromic coordination cage. Angew. Chem. Int. Ed. 2013, 52, 1319-1323.

(35) Kishi, N.; Akita, M.; Kamiya, M.; Hayashi, S.; Hsu, H.-F.; Yoshizawa, M. Facile Catch and Release of Fullerenes Using a Photoresponsive Molecular Tube. J. Am. Chem. Soc. 2013, 135, 12976-12979. 
(36) Murase, T.; Sato, S.; Fujita, M. Switching the Interior Hydrophobicity of a SelfAssembled Spherical Complex through the Photoisomerization of Confined Azobenzene Chromophores. Angew. Chem. Int. Ed. 2007, 46, 5133-5136.

(37) Chan, A. K.-W.; Lam, W. H.; Tanaka, Y.; Wong, K. M.-C.; Yam, V. W.-W. Multiaddressable molecular rectangles with reversible host-guest interactions: Modulation of pH-controlled guest release and capture. Proc. Natl. Acad. Sci. 2015, 112, 690-695.

(38) Riddell, I. A.; Smulders, M. M. J.; Clegg, J. K.; Nitschke, J. R. Encapsulation, storage and controlled release of sulfur hexafluoride from a metal-organic capsule. Chem. Commun. 2011, 47, 457-459.

(39) Gan, Q.; Ronson, T. K.; Vosburg, D. A.; Thoburn, J. D.; Nitschke, J. R. Cooperative loading and release behavior of a metal-organic receptor. J. Am. Chem. Soc. 2015, 137, 1770-1773.

(40) Preston, D.; Fox-Charles, A.; Lo, W. K. C.; Crowley, J. D. Chloride triggered reversible switching from a metallosupramolecular $\left[\mathrm{Pd}_{2} \mathrm{~L}_{4}\right]^{4+}$ cage to a $\left[\mathrm{Pd}_{2} \mathrm{~L}_{2} \mathrm{Cl}_{4}\right]$ metallomacrocycle with release of endo- and exo-hedrally bound guests. Chem. Commun. 2015, 51, 9042-9045.

(41) Wood, C. S.; Browne, C.; Wood, D. M.; Nitschke, J. R. Fuel-Controlled Reassembly of Metal-Organic Architectures. ACS Cent. Sci. 2015, 1, 504-509.

(42) Kishi, N.; Akita, M.; Yoshizawa, M. Selective Host-Guest Interactions of a Transformable Coordination Capsule/Tube with Fullerenes. Angew. Chem. Int. Ed. 2014, 53, 3604-3607.

(43) Lewis, J. E. M.; Gavey, E. L.; Cameron, S. A.; Crowley, J. D. Stimuli-responsive $\mathrm{Pd}_{2} \mathrm{~L}_{4}$ metallosupramolecular cages: towards targeted cisplatin drug delivery. Chem. Sci. 2012, 3, $778-784$.

(44) Qiu, Y.; Song, B.; Pezzato, C.; Shen, D.; Liu, W.; Zhang, L.; Feng, Y.; Guo, Q.H.; Cai, K.; Li, W.; Chen, H.; Nguyen, M. T.; Shi, Y.; Cheng, C.; Astumian, R. D.; Li, X.; Stoddart, J. F. A precise polyrotaxane synthesizer. Science 2020, 368, 1247-1253.

(45) Wang, Y.; Frasconi, M.; Stoddart, J. F. Introducing Stable Radicals into Molecular Machines. ACS Cent. Sci. 2017, 3, 927-935.

(46) Stoddart, J. F. Mechanically Interlocked Molecules (MIMs) - Molecular Shuttles, Switches, and Machines (Nobel Lecture). Angew. Chem. Int. Ed. 2017, 56, 11094-11125.

(47) Sun, W.-Y.; Kusukawa, T.; Fujita, M. Electrochemically Driven Clathration/Declathration of Ferrocene and Its Derivatives by a Nanometer-Sized Coordination Cage. J. Am. Chem. Soc. 2002, 124, 11570-11571.

(48) Colomban, C.; Szalóki, G.; Allain, M.; Gómez, L.; Goeb, S.; Sallé, M.; Costas, M.; Ribas, $\mathrm{X}$. Reversible $\mathrm{C}_{60}$ Ejection from a Metallocage through the Redox-Dependent Binding of a Competitive Guest. Chel. Eur. J. 2017, 23, 3016-3022.

(49) Fink, D.; Orth, N.; Linseis, M.; Ivanović-Burmazović, I.; Winter, R. F. Structural Versatility and Supramolecular Isomerism in Redox-Active Tetra- and Hexaruthenium Macrocycles. Eur. J. Inorg. Chem. 2020, 2020, 2816-2829.

(50) Fink, D.; Orth, N.; Ebel, V.; Gogesch, F. S.; Staiger, A.; Linseis, M.; IvanovićBurmazović, I.; Winter, R. F. Self-Assembled Redox-Active Tetraruthenium Macrocycles with Large Intracyclic Cavities. Organometallics 2020, 39, 1861-1880.

(51) Zaffaroni, R.; Bobylev, E. O.; Plessius, R.; van der Vlugt, J. I.; Reek, J. N. H. How to Control the Rate of Heterogeneous Electron Transfer across the Rim of $\mathrm{M}_{6} \mathrm{~L}_{12}$ and $\mathrm{M}_{12} \mathrm{~L}_{24}$ Nanospheres. J. Am. Chem. Soc. 2020, 142, 8837-8847. 
(52) Herasymchuk, K.; Miller, J. J.; MacNeil, G. A.; Sergeenko, A. S.; McKearney, D.; Goeb, S.; Sallé, M.; Leznoff, D. B.; Storr, T. Coordination-driven assembly of a supramolecular square and oxidation to a tetra-ligand radical species. Chem. Commun. 2019, 55, 6082-6085.

(53) Ube, H.; Endo, K.; Sato, H.; Shionoya, M. Synthesis of Hetero-multinuclear Metal Complexes by Site-Selective Redox Switching and Transmetalation on a Homomultinuclear Complex. J. Am. Chem. Soc. 2019, 141, 10384-10389.

(54) Winter, R. F. The molecular electrochemistry of metal-organic metallamacrocycles. Curr. Opin. Electrochem. 2018, 8, 14-23.

(55) Fink, D.; Weibert, B.; Winter, R. F. Redox-active tetraruthenium metallacycles: reversible release of up to eight electrons resulting in strong electrochromism. Chem. Commun. 2016, 52, 6103-6106.

(56) Croué, V.; Goeb, S.; Sallé, M. Metal-driven self-assembly: the case of redoxactive discrete architectures. Chem. Commun. 2015, 51, 7275-7289.

(57) Plessius, R.; Orth, N.; Ivanović-Burmazović, I.; Siegler, M. A.; Reek, J. N. H.; van der Vlugt, J. I. Reversible multi-electron storage in dual-site redox-active supramolecular cages. Chem. Commun. 2019, 55, 12619-12622.

(58) Bhattacharya, D.; Chang, C. H.; Cheng, Y. H.; Lai, L. L.; Lu, H. Y.; Lin, C. Y.; Lu, K. L. Multielectron redox chemistry of a neutral, NIR-active, indigo-pillared Re(I)-based triangular metalloprism. Chem. Eur. J. 2012, 18, 5275-5283.

(59) Furutani, Y.; Kandori, H.; Kawano, M.; Nakabayashi, K.; Yoshizawa, M.; Fujita, M. In situ spectroscopic, electrochemical, and theoretical studies of the photoinduced host-guest electron transfer that precedes unusual host-mediated alkane photooxidation. J. Am. Chem. Soc. 2009, 131, 4764-4768.

(60) Plessius, R.; Deij, V.; Reek, J. N. H.; van der Vlugt, J. I. Redox-Active Supramolecular Heteroleptic $\mathrm{M}_{4} \mathrm{~L}_{2} \mathrm{~L}_{2}^{\prime}$ Assemblies with Tunable Interior Binding Site. Chem. Eur. J. 2020, 26, 13241-13248.

(61) Mahata, K.; Frischmann, P. D.; Würthner, F. Giant electroactive $\mathrm{M}_{4} \mathrm{~L}_{6}$ tetrahedral host self-assembled with Fe(II) vertices and perylene bisimide dye edges. J. Am. Chem. Soc. 2013, 135, 15656-15661.

(62) You, C.-C.; Würthner, F. Self-Assembly of Ferrocene-Functionalized Perylene Bisimide Bridging Ligands with Pt(II) Corner to Electrochemically Active Molecular Squares. $J$. Am. Chem. Soc. 2003, 125, 9716-9725.

(63) Würthner, F.; Sautter, A. Highly fluorescent and electroactive molecular squares containing perylene bisimide ligands. Chem. Commun. 2000, 445-446.

(64) Lu, Z.; Ronson, T. K.; Nitschke, J. R. Reversible reduction drives anion ejection and C60 binding within an FeII4L6 cage. Chem. Sci. 2020, 11, 1097-1101.

(65) Yazaki, K.; Noda, S.; Tanaka, Y.; Sei, Y.; Akita, M.; Yoshizawa, M. An M2L4 Molecular Capsule with a Redox Switchable Polyradical Shell. Angew. Chem. Int. Ed. 2016, 55, 15031-15034.

(66) Xu, L.; Wang, Y. X.; Chen, L. J.; Yang, H. B. Construction of multiferrocenyl metallacycles and metallacages via coordination-driven self-assembly: from structure to functions. Chem. Soc. Rev. 2015, 44, 2148-2167.

(67) Jana, A.; Bähring, S.; Ishida, M.; Goeb, S.; Canevet, D.; Sallé, M.; Jeppesen, J. O.; Sessler, J. L. Functionalised tetrathiafulvalene- (TTF-) macrocycles: recent trends in applied supramolecular chemistry. Chem. Soc. Rev. 2018, 47, 5614-5645. 
(68) Canevet, D.; Sallé, M.; Zhang, G.; Zhang, D.; Zhu, D. Tetrathiafulvalene (TTF) derivatives: key building-blocks for switchable processes. Chem. Commun. 2009, 2245-2269.

(69) Segura, J. L.; Martín, N. New concepts in tetrathiafulvalene chemistry. Angew. Chem. Int. Ed. 2001, 40, 1372-1409.

(70) Martín, N. Tetrathiafulvalene: the advent of organic metals. Chem. Commun. 2013, 49, 7025-7027.

4890 .

(71) Batail, P. Introduction: Molecular Conductors. Chem. Rev. 2004, 104, 4887-

(72) Bryce, M. R. Functionalised tetrathiafulvalenes: new applications as versatile $\pi$ electron systems in materials chemistry. J. Mater. Chem. 2000, 10, 589-598.

(73) Nygaard, S.; Hansen, S. W.; Huffman, J. C.; Jensen, F.; Flood, A. H.; Jeppesen, J. O. Two Classes of Alongside Charge-Transfer Interactions Defined in One [2]Catenane. J. Am. Chem. Soc. 2007, 129, 7354-7363.

(74) Le Derf, F.; Mazari, M.; Mercier, N.; Levillain, E.; Trippé, G.; Riou, A.; Richomme, P.; Becher, J.; Garín, J.; Orduna, J.; Gallego-Planas, N.; Gorgues, A.; Sallé, M. Tetrathiafulvalene Crowns: Redox-Switchable Ligands. Chem. Eur. J. 2001, 7, 447-455.

(75) Mitamura, Y.; Yorimitsu, H.; Oshima, K.; Osuka, A. Straightforward access to aryl-substituted tetrathiafulvalenes by palladium-catalysed direct $\mathrm{C}-\mathrm{H}$ arylation and their photophysical and electrochemical properties. Chem. Sci. 2011, 2, 2017-2021.

(76) Goeb, S.; Bivaud, S.; Croué, V.; Vajpayee, V.; Allain, M.; Sallé, M. A SelfAssembled Electro-Active $\mathrm{M}_{8} \mathrm{~L}_{4}$ Cage Based on Tetrathiafulvalene Ligands. Materials 2014, 7 , 611-622.

(77) Vajpayee, V.; Bivaud, S.; Goeb, S.; Croué, V.; Allain, M.; Popp, B. V.; Garci, A.; Therrien, B.; Sallé, M. Electron-Rich Arene-Ruthenium Metalla-architectures Incorporating Tetrapyridyl-Tetrathiafulvene Donor Moieties. Organometallics 2014, 33, 1651-1658.

(78) Avram, L.; Cohen, Y. Diffusion NMR of molecular cages and capsules. Chem. Soc. Rev. 2015, 44, 586-602.

(79) Therrien, B. Arene Ruthenium Cages: Boxes Full of Surprises. Eur. J. Inorg. Chem. 2009, 2445-2453.

(80) Lau, J.; Blanchard, P.; Riou, A.; Jubault, M.; Cava, M. P.; Becher, J. Geometrically Constrained Tetrathiafulvalenophanes: Synthesis and Characterization. J. Org. Chem. 1997, 62, 4936-4942.

(81) Hansen, T. K.; Joergensen, T.; Jensen, F.; Thygesen, P. H.; Christiansen, K.; Hursthouse, M. B.; Harman, M. E.; Malik, M. A.; Girmay, B. Crown ether annelated tetrathiafulvalenes. J. Org. Chem. 1993, 58, 1359-1366.

(82) Balandier, J.-Y.; Chas, M.; Goeb, S.; Dron, P. I.; Rondeau, D.; Belyasmine, A.; Gallego, N.; Sallé, M. A self-assembled bis(pyrrolo)tetrathiafulvalene-based redox active square. New J. Chem. 2011, 35, 165-168.

(83) Balandier, J. Y.; Chas, M.; Dron, P. I.; Goeb, S.; Canevet, D.; Belyasmine, A.; Allain, M.; Sallé, M. N-Aryl Pyrrolo-tetrathiafulvalene Based Ligands: Synthesis and Metal Coordination. J. Org. Chem. 2010, 75, 1589-1599.

(84) Fujita, M.; Yazaki, J.; Ogura, K. Preparation of a macrocyclic polynuclear complex, [(en)Pd(4,4'-bpy) $]_{4}\left(\mathrm{NO}_{3}\right)_{8}$ (en = ethylenediamine, bpy = bipyridine), which recognizes an organic molecule in aqueous media. J. Am. Chem. Soc. 1990, 112, 5645-5647. 
(85) Stang, P. J.; Cao, D. H. Transition metal based cationic molecular boxes. Selfassembly of macrocyclic platinum(II) and palladium(II) tetranuclear complexes. J. Am. Chem. Soc. 1994, 116, 4981-4982.

(86) Goeb, S.; Bivaud, S.; Dron, P. I.; Balandier, J.-Y.; Chas, M.; Sallé, M. A BPTTFbased self-assembled electron-donating triangle capable of $\mathrm{C}_{60}$ binding. Chem. Commun. 2012, 48, 3106-3108.

(87) Ferrer, M.; Pedrosa, A.; Rodríguez, L.; Rossell, O.; Vilaseca, M. New Insights into the Factors That Govern the Square/Triangle Equilibria of $\mathrm{Pd}(\mathrm{II})$ and $\mathrm{Pt}(\mathrm{II})$ Supramolecules. Unexpected Participation of a Mononuclear Species in the Equilibrium. Inorg. Chem. 2010, 49, 9438-9449.

(88) Brunetti, F. G.; Lopez, J. L.; Atienza, C.; Martin, N. pi-Extended TTF: a versatile molecule for organic electronics. J. Mater. Chem. 2012, 22, 4188-4205.

(89) Moore, A. J.; Bryce, M. R. Highly conjugated $[\pi]$-electron donors for organic metals: synthesis and redox chemistry of new 1,3-dithiole and 1,3-selenathiole derivatives. $J$. Chem. Soc., Perkin Trans. 1 1991, 0, 157-168.

(90) Bryce, M. R.; Moore, A. J.; Hasan, M.; Ashwell, G. J.; Fraser, A. T.; Clegg, W.; Hursthouse, M. B.; Karaulov, A. I. Electrical and Magnetic Properties and X-Ray Structure of a Highly Conductive 4:1 Complex of Tetracyanoquinodimethane and a Tetrathiafulvalene Derivative. Angew. Chem. Int. Ed. 1990, 29, 1450-1452.

(91) Yamashita, Y.; Kobayashi, Y.; Miyashi, T. p-Quinodimethane Analogues of Tetrathiafulvalene. Angew. Chem. Int. Ed. 1989, 28, 1052-1053.

(92) Szalóki, G.; Krykun, S.; Croué, V.; Allain, M.; Morille, Y.; Aubriet, F.; Carré, V.; Voitenko, Z.; Goeb, S.; Sallé, M. Redox-Driven Transformation of a Discrete Molecular Cage into an Infinite 3D Coordination Polymer. Chem. Eur. J. 2018, 24, 11273-11277.

(93) Bivaud, S.; Goeb, S.; Croué, V.; Allain, M.; Pop, F.; Sallé, M. Tuning the size of a redox-active tetrathiafulvalene-based self-assembled ring. Beilstein J. Org. Chem. 2015, 11, 966-971.

(94) Bivaud, S.; Goeb, S.; Croué, V.; Dron, P. I.; Allain, M.; Sallé, M. Self-Assembled Containers Based on Extended Tetrathiafulvalene. J. Am. Chem. Soc. 2013, 135, 10018-10021.

(95) Thanasekaran, P.; Lee, C.-H.; Lu, K.-L. Neutral discrete metal-organic cyclic architectures: Opportunities for structural features and properties in confined spaces. Coord. Chem. Rev. 2014, 280, 96-175.

(96) Chakrabarty, R.; Mukherjee, P. S.; Stang, P. J. Supramolecular coordination: selfassembly of finite two- and three-dimensional ensembles. Chem. Rev. 2011, 111, 6810-6918.

(97) Ahmad, N.; Chughtai, A. H.; Younus, H. A.; Verpoort, F. Discrete metalcarboxylate self-assembled cages: Design, synthesis and applications. Coord. Chem. Rev. 2014, $280,1-27$.

(98) Szalóki, G.; Croué, V.; Allain, M.; Goeb, S.; Sallé, M. Neutral versus polycationic coordination cages: a comparison regarding neutral guest inclusion. Chem. Commun. 2016, 52, 10012-10015.

(99) Perepichka, D. F.; Perepichka, I. F.; Ivasenko, O.; Moore, A. J.; Bryce, M. R.; Kuz'mina, L. G.; Batsanov, A. S.; Sokolov, N. I. Combining High Electron Affinity and Intramolecular Charge Transfer in 1,3-Dithiole-Nitrofluorene Push-Pull Diads. Chem. Eur. J. 2008, 14, 2757-2770.

(100) Amriou, S.; Wang, C.; Batsanov, A. S.; Bryce, M. R.; Perepichka, D. F.; Ortí, E.; Viruela, R.; Vidal-Gancedo, J.; Rovira, C. The Interplay of Inverted Redox Potentials and 
Aromaticity in the Oxidized States of New $\pi$-Electron Donors: 9-(1,3-Dithiol-2-ylidene)fluorene and 9-(1,3-Dithiol-2-ylidene)thioxanthene Derivatives. Chem. Eur. J. 2006, 12, 3389-3400.

(101) Bloch, W. M.; Clever, G. H. Integrative self-sorting of coordination cages based on 'naked' metal ions. Chem. Commun. 2017, 53, 8506-8516.

(102) Han, M.; Engelhard, D. M.; Clever, G. H. Self-assembled coordination cages based on banana-shaped ligands. Chem. Soc. Rev. 2014, 43, 1848-1860.

(103) Croué, V.; Krykun, S.; Allain, M.; Morille, Y.; Aubriet, F.; Carré, V.; Voitenko, Z.; Goeb, S.; Sallé, M. A self-assembled $\mathrm{M}_{2} \mathrm{~L}_{4}$ cage incorporating electron-rich 9-(1,3-dithiol-2ylidene)fluorene units. New J. Chem. 2017, 41, 3238-3241.

(104) Dekhtiarenko, M.; Krykun, S.; Carré, V.; Aubriet, F.; Canevet, D.; Allain, M.; Voitenko, Z.; Sallé, M.; Goeb, S. Tuning the structure and the properties of dithiafulvene metalla-assembled tweezers. Org. Chem. Front. 2020, 7, 2040-2046.

(105) Cotelle, Y.; Hardouin-Lerouge, M.; Legoupy, S.; Alévêque, O.; Levillain, E.; Hudhomme, P. Glycoluril-tetrathiafulvalene molecular clips: on the influence of electronic and spatial properties for binding neutral accepting guests. Beilstein J. Org. Chem. 2015, 11, 10231036.

(106) Chen, L.; Zhang, Y.-C.; Wang, W.-K.; Tian, J.; Zhang, L.; Wang, H.; Zhang, D.W.; Li, Z.-T. Conjugated radical cation dimerization-driven generation of supramolecular architectures. Chin. Chem. Lett. 2015, 26, 811-816.

(107) Zhang, D.-W.; Tian, J.; Chen, L.; Zhang, L.; Li, Z.-T. Dimerization of Conjugated Radical Cations: An Emerging Non-Covalent Interaction for Self-Assembly. Chem. Asian J. 2014, 10, 56-68.

(108) Rosokha, S. V.; Kochi, J. K. Fresh Look at Electron-Transfer Mechanisms via the Donor/Acceptor Bindings in the Critical Encounter Complex. Acc. Chem. Res. 2008, 41, 641653.

(109) Rosokha, S. V.; Kochi, J. K. Molecular and Electronic Structures of the LongBonded $\pi$-Dimers of Tetrathiafulvalene Cation-Radical in Intermolecular Electron Transfer and in (Solid-State) Conductivity. J. Am. Chem. Soc. 2007, 129, 828-838.

(110) Kahlfuss, C.; Saint-Aman, E.; Bucher, C. Redox-Controlled Intramolecular Motions Triggered by $\pi$-Dimerization and Pimerization Processes. Wiley Online Library 2015, 39-88.

(111) Aparicio, F.; Faour, L.; Allain, M.; Canevet, D.; Sallé, M. A pyrenefunctionalized foldamer: structural impact and recognition properties supported by donoracceptor interactions. Chem. Commun. 2017, 53, 12028-12031. 


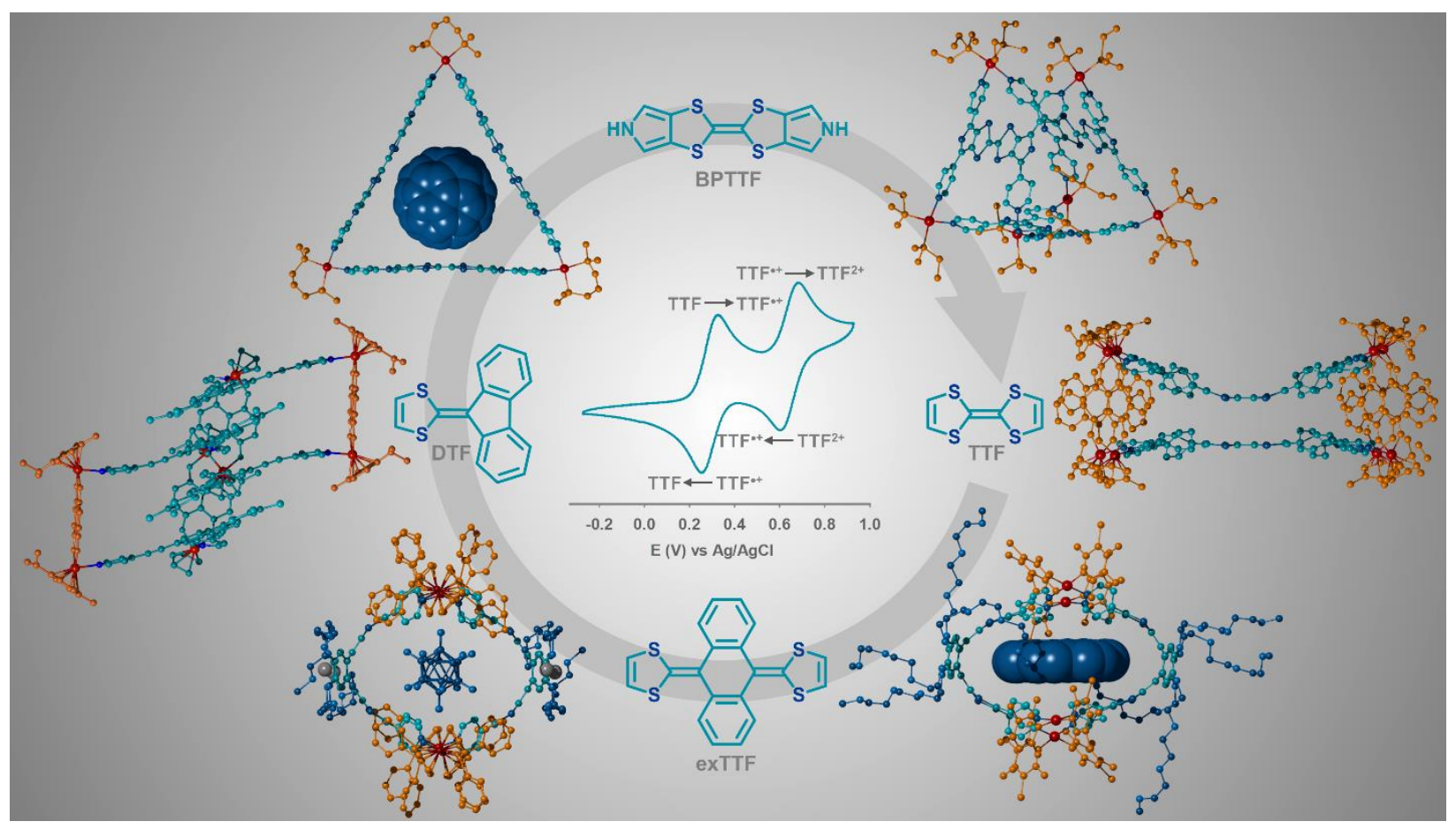

